This PDF is a selection from an out-of-print volume from the National Bureau of Economic Research

Volume Title: The Quality and Economic Significance of Anticipations Data

Volume Author/Editor: Universities-National Bureau Committee for

Economic Research

Volume Publisher: Princeton University Press

Volume ISBN: 0-87014-301-8

Volume URL: http://www.nber.org/books/univ60-1

Publication Date: 1960

Chapter Title: The Formation of Business Expectations about Operating Variables

Chapter Author: Millard Hastay

Chapter URL: http://www.nber.org/chapters/c6595

Chapter pages in book: (p. 91 -148) 


\title{
The Formation of Business Expectations About Operating Variables
}

\author{
MILLARD HASTAY
}

\section{STATE COLLEGE OF WASHINGTON}

This paper is a report on one phase of a general exploratory study of the Dun and Bradstreet quarterly surveys of businessmen's expectations. The aim of the study has been to find out what use can be made of data on business expectations about operating variables, in distinction from the more familiar data on planned capital expenditures compiled in the Department of Commerce-Securities and Exchange Commission and McGraw-Hill surveys. The present phase of the research has been organized around two basic problems:

1. The rationality of business expectations about operating variables

2. Realized business behavior under conditions of uncertainty.

The first problem involves such questions as whether business expectations disclose self-consistent relations between prospects and plans and whether they are significantly related to past experience. Appraising the results of an attempt to fit models of business expectations to the Dun and Bradstreet data offers a way of looking into this question of rationality.

Under the second heading the central question is whether incorrect expectations have a binding effect on subsequent behavior. Businessmen must act on estimates of the future that often prove wrong, and they are more or less hampered in adjusting to revised estimates as the errors are discovered. What is the evidence that this uncertainty leads to different actions than a correct forecast would have done, and how important are the effects of the uncertainty? The complex of questions involved here is being investigated by trying to fit to the data models of realized behavior in which expectations figure as explicit determinants. 1

It need hardly be argued that models of the two types are closely related. In fact, answers to questions about the influence of expectations on realized behavior depend critically on the character of the findings about the formation of expectations. Nevertheless, as a technical matter, the two

\footnotetext{
1 The work of Franco Modigliani on expectations theory ("The Role of Anticipations and Plans in the Economy of the Firm and their Use in Economic Analysis and Forecasting," Mary Jean Bowman, ed., Expectations, Uncertainty, and Business Behavior, conference sponsored by the Social Science Research Council at the Carnegie Institute of Technology, October 27-29, 1955), and of Henri Theil on statistical methodology ("Forecasts and Economic Policy," Amsterdam, 1959) encouraged the pursuit of this line of research.
} 
types of models permit of separate study and can be estimated independently. The priority of the subject of expectation formation has dictated the decision to take it up first. This paper is a report on what has been learned concerning the rationality of business expectations about operating variables. Apart from certain by-products of the expectations study, a discussion of the findings on realized behavior under conditions of uncertainty is left to a subsequent report.

\section{Concepts and Data}

In analyzing business expectations, a basic consideration is whether the expectations refer to "action parameters" (also called "instruments") or to data. The distinction depends upon how far the relevant variables are under the control of the individual firm. In this context, business expectations can be classified as intentions-plans for action in matters where the firm can make binding decisions; market anticipations-expectations about events that result from the interplay between the firm's actions and its environment; and outlook-expectations about general business conditions which the firm cannot perceptibly influence but which will help to determine the strength of its markets. ${ }^{2}$

\section{THE DUN AND BRADSTREET SURVEYS ${ }^{3}$}

The Dun and Bradstreet "Surveys of Businessmen's Expectations" are quarterly surveys of short-run intentions (for employment, inventories, and perhaps prices) and of anticipations (for new orders, sales, and profits). Since the third quarter of 1951 the sample has never fallen below 1,000 firms and today includes around 1,400. Although the data refer wholly to activity within individual firms, they are aggregated into four broad industrial groups: durable goods manufacturers, nondurable goods manufacturers, wholesalers, and retailers. Each survey yields evidence on sales, employment, inventories, prices, and profits for all four groups, plus new orders for the two manufacturing groups.

The business firms interviewed are a sample drawn from about 54,000 medium-to-large firms of sufficient credit interest to justify re-investigation roughly twice a year. During a two-week period around the close of each calendar quarter the expectations survey is grafted on to the regular credit interviews. The reporters are instructed to prepare a questionnaire for each firm contacted until certain pre-established quotas are met.

Each questionnaire asks for expectations for a period terminating two

2 The terminology used here is consistent with that used in An Appraisal of Data and Research on Businessmen's Expectations about Outlook and Operating Variables, Report of the Consultant Committee on General Business Expectations, Board of Governors of the Federal Reserve System, September 1955; see especially Chap. II, pp. 8-9.

3 For a more complete description of the surveys, together with evidence bearing on the quality of the data, see ibid., Chap. III, pp. 25-34. 
quarters ahead and for actual developments for a period terminating in the quarter just closed. Thus a check on expectations is provided by the reports on actual experience compiled in the survey taken two quarters later, but the two sets of data come from different samples. Consequently problems of sampling variability make comparison of expectations with actual outcomes difficult.

The published Dun and Bradstreet reports show, for each variable and industrial group, the percentage distribution of sampled firms that actually experienced a rise, no change, or a fall in the one-year period just concluded, and a similar distribution describing their expectations for the overlapping one-year period ending two quarters hence. This technique of making comparisons with the corresponding quarter of the previous year and the timing of the surveys for the lașt quarter covered, blur the distinction between reported expectations and reported realized experience: Such ambiguities are the price paid for the rapid availability of the reports-typically within three weeks of the close of the final quarter covered-and for the elimination of seasonal variations. Further, qualitative reports on direction of change are not only quicker, but they may appeal to executives who might be reluctant to give absolute figures.

Three criticisms of the Dun and Bradstreet surveys are that the sample is haphazard, that the reports are biased because of the credit-rating connection of the compiler, and that uninformed subordinates give the answers. There are various possible answers to the criticisms, ${ }^{4}$ but final judgment will depend on the success of efforts to use the data the surveys provide. The population sampled-whatever it is-may behave much like the business population at large, and a more or less constant bias in the answers can be allowed for statistically.

\section{DIFFUSION INDEXES 5}

Qualitative results of the sort tabulated by Dun and Bradstreet are called "diffusion data" since they indicate the number of firms sharing in, or the scope of, a given movement, expressed as a percentage of the total number of firms in the collection. Particular changes in a set of individualfirm variables are frequently called "microchanges"; the change in the corresponding aggregate, a "macrochange." Diffusion data comprise the distribution of signs of microchanges. To analyze the movements, a

4 ibid., pp. 28-32.

5 For more complete discussions of diffusion indexes, see Geoffrey $\mathrm{H}$. Moore, "Diffusion Indexes: A Comment," American Statistician, October 1955, pp. 13-17 and 30; Henri Theil and J. S. Cramer, "On the Utilization of a New Source of Economic Information: An Econometric Analysis of the Munich Business Test," a paper presented at the 16th European Meeting of the Econometric Society, Uppsala, Sweden, August 1954; and Millard Hastay, "The Dun and Bradstreet Surveys of Businessmen's Expectations," Proceedings of the Business and Economic Statistics Section, 114th Annual Meeting of the American Statistical Association, 1955, pp. 93-123. 
"diffusion index" is used, which measures the net excess of the percentage of rising movements over the percentage of declining movements, usually well within the possible range of -100 per cent to +100 per cent. Though no explicit account is taken of the percentage of series undergoing no change, it is allowed for implicitly since the diffusion index formula implies that any instance of reported no change has a 50:50 chance of being a rise or a decline.

The results of various studies suggest that weighting diffusion data enhances their value as proxies for conventional economic aggregates. Since the second quarter of 1953 Dun and Bradstreet has compiled information on the net tangible assets of the firms interviewed, by means of which it classifies them into ten size groups (Table 1). These data make possible two weighting schemes:

TABLE 1

Percentage Distribution of Respondents by Capital Rating Groups, Dun and Bradstreet Surveys of Businessmen's Expectations, 1953-1956

\begin{tabular}{|c|c|c|c|c|c|c|c|c|}
\hline \multirow[b]{2}{*}{$\begin{array}{c}\text { ESTIMATED TANGIBLE } \\
\text { NET WORTH }\end{array}$} & \multicolumn{2}{|c|}{$\begin{array}{l}\text { DURABLE } \\
\text { GOODS MANU- } \\
\text { FACTURERS }\end{array}$} & \multicolumn{2}{|c|}{$\begin{array}{l}\text { NONDURABLE } \\
\text { GOODS MANU- } \\
\text { FACTURERS }\end{array}$} & \multicolumn{2}{|c|}{ WHOLESALERS } & \multicolumn{2}{|c|}{ RETAILERS } \\
\hline & Firms & $\begin{array}{c}\text { Net } \\
\text { Worth }\end{array}$ & Firms & $\begin{array}{c}\text { Net } \\
\text { Worth }\end{array}$ & Firms & $\begin{array}{c}\text { Net } \\
\text { Worth }\end{array}$ & Firms & $\begin{array}{c}\text { Net } \\
\text { Worth }\end{array}$ \\
\hline$\$ 1,000,000$ and over & 29 & 91.9 & 23 & 90.1 & 12 & 58.0 & 13 & 84.9 \\
\hline $750,000-\$ 999,999$ & 6 & 1.9 & 5 & 1.9 & 4 & 5.5 & 4 & 2.4 \\
\hline $500,000-749,999$ & 11 & 2.2 & 10 & 2.5 & 8 & 9.4 & 8 & $3 \cdot 5$ \\
\hline $300,000-499,999$ & 15 & 2.0 & 15 & 2.5 & 15 & 10.5 & 13 & 3.6 \\
\hline $200,000-299,999$ & 11 & 0.9 & 14 & 1.4 & 16 & 7.3 & 12 & 2.0 \\
\hline $125,000-199,999$ & 13 & 0.7 & 15 & 1.0 & 19 & 5.6 & 17 & 1.9 \\
\hline $75,000-124,999$ & 9 & 0.3 & 12 & 0.5 & 15 & 2.7 & 15 & 1.0 \\
\hline $50,000-74,999$ & 4 & 0.1 & 4 & 0.1 & 6 & 0.6 & 8 & 0.3 \\
\hline $35,000-\quad 49,999$ & 2 & a & 1 & $\mathbf{a}$ & 2 & 0.2 & 5 & 0.1 \\
\hline Under $\$ 35,000$ & 2 & $\mathbf{a}$ & 1 & a & 2 & 0.1 & 5 & 0.1 \\
\hline Total & $\overline{100}$ & $\overline{100.0}$ & $\overline{100}$ & $\overline{100.0}$ & $\overline{100}$ & $\overline{100.0}$ & $\overline{100}$ & $\overline{100.0}$ \\
\hline
\end{tabular}

In this and the following tables, detail may not sum to totals because of rounding.

Respondents are those replying to questions on sales expectations, excluding a small number of firms for which capital ratings were not reported.

a Under 0.05 .

Type I Weights-This scheme merely standardizes the samples for firm-size coverage. A simple diffusion index is computed for each class, and these are combined with weights proportional to the average percentage of firms in each class. Such indexes were calculated for the fifteen surveys made in the period II 1953-IV 1956.

Type II Weights-The second scheme achieves the objective of the first and also a rough weighting of diffusion experience according to the 
economic importance of each respondent. Each asset class is represented by its mid-value, except for the open-end class of largest firms, for which average values based on a more than 5 per cent random sample of firms with net tangible assets over $\$ 1$ million is used. Since no breakdown between durable goods and nondurable goods manufacturers was available, the same average net worth is assumed for both manufacturing groups. Such indexes were calculated for the same period as for the Type I weights.

Unweighted-Simple indexes were also calculated for the thirty surveys made in the period II 1949-I 1957.

In the following discussion Theil's notation will be used. The macrovariable under consideration will be denoted $X$, the diffusion index of realized microchanges will be denoted $b(X)$, and the diffusion index of expected microchanges, $b(\bar{X})$. The diffusion index is necessarily dated. If it refers to an interval terminating in the present, it bears no subscript; if to an interval terminating in the previous quarter, it will be written $b(X)_{-1}$ for realized diffusion, $b(\bar{X})_{-1}$ for expected diffusion. Since Dun and Bradstreet expectations refer to a situation two quarters after the survey compared with the corresponding situation a year earlier, $b(\bar{X})$ refers to expectations formed two quarters earlier, while the diffusion of current expectations must be denoted $b(\bar{X})_{+2}$. Thus today's survey yields a diffusion index of expected sales $b(\bar{S})_{+2}$ and another of realized sales $b(S)$. The latter index is to be compared with the diffusion of sales expected two surveys ago $b(\bar{S})$, and two surveys hence we shall have a diffusion index of realized sales $b(S)_{+2}$ to compare with today's expectations.

\section{Models of the Formation of Expectations}

The hypothesis that expectations have an essential role in shaping realized behavior makes most sense for variables over which firms have a measure of control. From this standpoint, the chief candidate for attention is inventory investment-the inventory adjustments which businessmen intend to make and the factors which shape these intentions. While expected inventory change in the very short run may be "given," over two quarters it will represent a target to be reached through procurement and production adjustments. We will thus be primarily concerned with the formation of expectations rather than of anticipations, seeking to explain changes in the instruments of decision-making, and concerned with data only as they influence the decisions about instruments.

\section{INTENDED INVENTORY INVESTMENT}

The main elements in inventory planning are fairly well understood. The influence of the following factors on inventory planning can be 
measured through the behavior of one or more variables in the Dun and Bradstreet surveys:

"Acceleration principle" (varying inventory with the expected rate of change in sales) through the diffusion of expected sales, $b(\bar{S})$

"Purchase-price speculation" (hedging for expected buying-price rises) through the diffusion of expected buying prices, $b\left(\bar{p}_{h}\right)$

"Risk aversion" (allowing for possible market deterioration) through the diffusion of expected selling prices, $b(\bar{p})$

"Stock appraisal" (equating current inventories to current needs) through a comparison of the diffusion of prior inventory intentions with the diffusion of corresponding outcomes, $[b(H)-b(\bar{H})]$.

In constructing a model of inventory intentions for diffusion data, we can draw on the close connection between diffusion and aggregate change and think of inventory investment as varying in proportion to inventory diffusion, $b(H)$; of the change in sales as varying in proportion to sales diffusion, $b(S)$; of unintended inventory change as varying in proportion to the excess of realized inventory diffusion over the prior diffusion of inventory intentions, $[b(H)-b(\bar{H})]$; and so on. Then analogy suggests the following equation as an explanation of the diffusion of inventory intentions:

$$
b(\bar{H})=a_{1} b(\bar{S})+a_{2} b(\bar{p})+a_{3} b\left(\bar{p}_{h}\right)+a_{4}\left[b(H)_{-2}-b(\bar{H})_{-2}\right]+a_{0}+u_{1}
$$

The terms $a_{1} b(\bar{S})+a_{4}\left[b(H)_{-2}-b(\bar{H})_{-2}\right]$ provide a fairly realistic representation of an acceleration principle that makes allowance for preexisting stocks. The term $a_{3} b\left(\bar{p}_{h}\right)$ measures the speculative impact on inventory investment of expected changes in buying prices. And $a_{2} b(\bar{p})$ allows for the influence of expected selling-price variations on the appraisal of speculative risk. The linearity of the relation is a practical approximation. It may be thought to hold within a range of moderate fluctuations about an underlying position of stock equilibrium. The term $u_{1}$ is an acknowledgement that the relation holds stochastically, and we assumewith some justification for time series akin to quarterly first differencesthat successive values of $u_{1}$ are statistically independent.

Though Dun and Bradstreet do not compile data on buying prices, manufacturers' selling prices may be treated as proxy for wholesalers' buying prices, and wholesalers' selling prices as proxy for retailers' buying prices, but no buying prices for manufacturers can be inferred. However, because of doubts about this proxy, and to facilitate comparisons between manufacturers and traders, we employ, for the present, for both groups, an equation omitting buying prices:

$$
b(\bar{H})=a_{1} b(\bar{S})+a_{2} b(\bar{p})+a_{4}\left[b(H)_{-2}-b(\bar{H})_{-2}\right]+a_{0}+u_{1}
$$




\section{EXPECTATIONS ABOUT OPERATING VARIABLES}

The price of thus truncating the inventory equation may be less than it at first seems. Theil showed that in the hides-leather-shoe production sequence in West Germany, selling prices, both actual and planned, were almost wholly dominated by actual and expected buying prices; and United States manufacturers' buying prices may also vary much as their selling prices do. ${ }^{6}$ Combined with the fact that the coefficients $a_{2}$ and $a_{3}$ may be expected to have the same sign, the truncated manufacturers' equation may reflect much of the influence of buying-price anticipations in the coefficient of the selling-price variable. Whether this argument applies with equal force to traders is uncertain, bat it seems reasonably in accord with what we know about price behavior in the trade field.

The theory outlined above clearly implies that $a_{1}, a_{2}$, and $a_{3}$ are intrinsically positive, though a high degree of collinearity between $b(\bar{p})$ and $b\left(p_{h}\right)_{-2}$ may make it difficult to estimate $a_{2}$ and $a_{3}$ with precision. The sign of $a_{4}$ is less certain. We can, in fact, distinguish three cases:

1. Substantial production plan inertia, so that the production plan based on $b(\bar{H})_{-2}$ is substantially carried out. Then over-optimism implies $\left[b(H)_{-2}-b(\bar{H})_{-2}\right]>0$, and conversely; whence $a_{4}$ negative.

2. Production plans are flexible, but not sufficiently so to keep up with changed intentions. Then overoptimism implies that $b(H)_{-2}$ is cut back below $b(\bar{H})_{-2}$ so that $\left[b(H)_{-2}-b(\bar{H})_{-2}\right]<0$, and conversely; in this case $a_{4}$ is positive. This may happen even with perfect adjustment of realized inventory accumulation to "final" intentions, reflecting a revision of general economic appraisals in line with changed inventory requirements; but $a_{4}=0$ may also occur, with the changed outlook appraisal affecting $b(\bar{S})$ and $b(\bar{p})$ for the next period.

3. Just sufficient plan flexibility so that $\left[b(H)_{-2}-b(\bar{H})_{-2}\right]$ remains in the neighborhood of zero. Then $a_{4}$ will tend to be nonsignificant without carrying the implication that inventory adjustment is typically in shortrun equilibrium.

\section{COMPLETION OF MODELS OF EXPECTATION FORMATION}

The equation for inventories contains two variables that must be regarded as determined along with inventory intentions: expected sales and expected selling prices. Since the buying-price variable used in the traders' model represents the ex post diffusion of selling prices of the preceding stage of business activity, it can be treated as predetermined in the same sense as $b(H)_{-2}$ and $b(\bar{H})_{-2}$ are predetermined. To complete the models of expectation formation, equations for sales and price expectations must be adjoined, with buying prices still omitted from the traders' model as well as from the manufacturers' model.

6 Henri Theil, "Recent Experiences with the Munich Business Test," Econometrica, April 1955, pp. 184-192. 
Sales Anticipations. The equation for manufacturers' sales anticipations differs from that for traders in two respects: in providing for the role of new orders, and in allowing for the possibility that manufacturers' prices are instruments of deliberate control. We thus have:

Manufacturers

$$
h(\bar{S})=b_{1} b(\bar{p})+b_{2}\left[b(p)_{-2}-b(\bar{p})_{-2}\right]+b_{3} b(N)_{-2}+b_{0}+u_{2}
$$

Traders

$$
b(\bar{S})=c_{1} b(S)_{-2}+c_{2}\left[b(S)_{-2}-b(\bar{S})_{-2}\right]+c_{0}+u_{3}
$$

Treating traders as price takers reduces the equation for their sales anticipations to a simple learning model. By contrast, recognizing that manufacturers may defer making intended price adjustments and that this deferment may affect their sales outlook, requires the introduction of a term in $\left[b(p)_{-2}-b(\bar{p})_{-2}\right]$. The use of new orders as a barometer of prospective sales needs no argument, but the choice of realized rather than anticipated new orders does. The economic justification is that new orders lead sales; thus it is orders in hand that dominate next period's sales, rather than orders in prospect. Moreover, in the Dun and Bradstreet surveys, anticipated new orders fail to show a reasonable lead over anticipated sales, suggesting that businessmen base their new order and sales anticipations on essentially the same evidence. Inclusion of anticipated new orders would merely have complicated the model and introduced a possible indeterminacy.

Selling-Price Expectations. The differing degree of control over prices by manufacturers and traders is recognized also in the equations for expected price diffusion. In both equations, expected price changes depend on anticipated changes in sales, but the effect of deferred price adjustments by manufacturers is admitted as an added factor. As price takers, traders are also assumed to base their anticipations on the recent trend of prices. Finally, both manufacturers and traders are assumed to adjust their price expectations to an appraisal of current stocks. The role of disequilibrium stocks seems sufficiently important to warrant the use of the variable $\left[b(H)_{-2}-b(\bar{H})_{-2}\right]$ despite its inherent ambiguity. The equations of price expectations thus become:

Manufacturers

$$
b(\bar{p})=d_{1} b(\bar{S})+d_{2}\left[b(p)_{-2}-b(\bar{p})_{-2}\right]+d_{3}\left[b(H)_{-2}-b(\bar{H})_{-2}\right]+d_{0}+u_{4}
$$

Traders

$$
b(\bar{p})=g_{1} b(\bar{S})+g_{2} b(p)_{-2}+g_{3}\left[b(H)_{-2}-b(\bar{H})_{-2}\right]+g_{0}+u_{5}
$$

AN ALTERNATIVE MODEL FOR MANUFACTURERS

The three equations which comprise the traders' model, equations 2, 4, and 6, have the interesting property of "recursiveness." By this is meant 
that the interdependence of current expectations can be viewed as a causal chain: $b(\bar{S})$ depends only on predetermined variables, $b(\bar{p})$ depends additionally on $b(\bar{S})$, while $b(\bar{H})$ depends on predetermined variables and both $b(\bar{S})$ and $b(\bar{p})$. Thus each equation can be given a unilateral causal interpretation. The formation of traders' expectations is viewed as beginning with a sales forecast, passing to a price anticipation, and terminating with an inventory objective.

Recursive models of this sort have a strong appeal as representations of intellectual processes. Static equilibrium theory has conditioned economists to think of amount of sales and price as being determined by a pair of simultaneous equations, but it is implausible to suppose that expectations about sales and prices result from the mental solution of equations of the same sort. Consequently there is reason to be dissatisfied with the manufacturers' model, equations 2, 3, and 5. Equation 3 tells us that sales expectations depend on price expectations, whereas equation 5 tells us that price expectations depend on sales expectations. Logic is not thereby violated, but our intuitive experience of intellectual processes is. A recursive model of manufacturers' expectations therefore follows:

$$
\begin{gathered}
b(\bar{H})=\text { same as above } \\
b(\bar{S})=b_{1} b(\bar{p})+b_{2} b(S)_{-2}+b_{3} b(N)_{-2}+b_{0}+u_{2} \\
b(\bar{p})=d_{1} b(p)_{-2}+d_{2} b(N)_{-2}+d_{3}\left[b(p)_{-2}-b(\bar{p})_{-2}\right] \\
+d_{4}\left[b(H)_{-2}-b(\bar{H})_{-2}\right]+d_{0}+u_{4}
\end{gathered}
$$

The choice of $b(\bar{p})$ instead of $b(\bar{S})$ as the initial variable in the causal chain reflects the view that manufacturers tend to treat prices as instruments of control rather than as data. The required change of equation 5 is accomplished by substituting $b(N)_{-2}$ for $b(\bar{S})$ as a measure of demand strength, and by adding $b(p)_{-2}$ as a reflection of price trends. The modification of equation 3 is not strictly necessary for recursiveness. It arises from the belief that recent sales experience as well as new orders received affects sales anticipations. It also reflects the feeling that $\left[b(p)_{-2}-b(\bar{p})_{-2}\right]$ is redundant since its effect on demand should be reflected in $b(N)_{-2}$, while its impact on price intentions should show up in $b(\bar{p})$. As finally modified, the model implies that the process of expectation formation for manufacturers begins with a price expectation, passes to a compatible sales estimate, and ends with an inventory objective.

\section{Statistical Evaluation of the Models}

When we come to empirical testing, the first consideration is whether the models are "identified." Given sufficient empirical information, would it be possible to determine unique values for the coefficients of the various equations? 
The Dun and Bradstreet data comprise a set of "solutions" of the model. Since there are generally more solutions than unknown parameters, and since the solutions differ in part for unexplained reasons, some principle of reconciliation, such as least squares, must be employed. However, the principle cannot be depended on to yield unique estimates unless the equations of the model are suitably restricted. Though the stochastic character of the problem admits of other possibilities, the restrictions employed are that certain coefficients in each equation shall be zero, or (what amounts to the same thing) that certain variables shall be absent from each.

Modern statistical theory establishes a close connection between the notion of identification and valid techniques of estimation. A nonidentified equation admits of no valid method of estimation. An exactly identified equation can be evaluated by an indirect application of least squares known as the reduced form method. The equations of a recursive model are always identified, and can be evaluated by least squares either directly or by a suitable process of serial application. The methods of estimation used in this paper are wholly based on least squares because the models involved are either recursive (traders' model and alternative manufacturers' model) or exactly identified (original manufacturers' model). ${ }^{7}$

\section{MANUFACTURERS' EXPECTATIONS}

Exactly Identified Model. The nonrecursive model of manufacturers' expectations illustrates the problems that arise in using the technique of indirect least squares to estimate the coefficients of diffusion models, manifested as a disturbing instability in the pattern of findings. Consider, for example, Table 2, which presents the results of evaluating the manufacturers' model in terms of diffusion data.

Different weighting schemes and the industrial contrasts between durable and nondurable goods manufacturers, bespeak the probability of substantial differences between the four models shown. Moreover, with the possible exception of the acceleration coefficient $(-0.26)$ for durable goods manufacturers (Type II Weights), there is no weighted estimate that is clearly inconsistent with the manufacturers' model under consideration. Production and procurement policy seem sufficiently flexible so that the departure of realized inventory accumulation from prior intentions is usually in the right direction, though probably not in the right amount. Price policy shows comparable flexibility among durable goods manufacturers, but not among nondurables manufacturers. Also

${ }^{7}$ For more complete discussions of the methods of estimation used, see Tjalling C. Koopmans, "Identification Problems in Economic Model Construction," and Tjalling C. Koopmans and William C. Hood, "The Estimation of Simultaneous Linear Economic Relationships," both in Studies in Econometric Method, Cowles Commission Monograph 14, Wiley, 1953; Herman Wold, Demand Analysis: A Study in Econometrics, Wiley, 1953, pp. 49-53; and Lawrence R. Klein, A Textbook of Econometrics, Wiley, 1953, pp. 80-92. 
TABLE 2

Formation of Manufacturers' Expectations as Reflected in Diffusion Data, Exactly Identified Model

COEFFICIENTS OF EXPLANATORY VARIABLES

\begin{tabular}{|c|c|c|c|c|c|c|}
\hline \multirow[b]{2}{*}{$\begin{array}{l}\text { EXPECTATIONAL } \\
\text { VARIABLE }\end{array}$} & \multicolumn{2}{|c|}{ Expectation } & \multicolumn{2}{|c|}{$\begin{array}{c}\text { Actual minus } \\
\text { Expected, Lagged } \\
\end{array}$} & \multirow[b]{2}{*}{$\frac{\text { Actual, Lagged }}{\text { New Orders }}$} & \multirow[b]{2}{*}{ Constant } \\
\hline & Sales & $\begin{array}{l}\text { Selling } \\
\text { Prices }\end{array}$ & $\begin{array}{l}\text { Inven- } \\
\text { tory }\end{array}$ & Prices & & \\
\hline \multicolumn{7}{|c|}{$\begin{array}{l}\text { TYPE I WEIGHTS } \\
\text { urable Goods Manufacturers }\end{array}$} \\
\hline Inventories & +0.59 & +0.05 & +0.18 & & & -0.18 \\
\hline Sales & & -0.15 & & +0.39 & +0.62 & +0.26 \\
\hline Selling prices & +0.70 & & +0.20 & +0.28 & & -0.18 \\
\hline \multicolumn{7}{|c|}{ Nondurable Goods Manufacturers } \\
\hline Inventories & +0.51 & +0.40 & +0.08 & & & -0.22 \\
\hline Sales & & +1.42 & & -1.52 & +0.21 & +0.28 \\
\hline Selling prices & +0.48 & & +0.09 & +1.01 & & -0.13 \\
\hline \multicolumn{7}{|c|}{$\begin{array}{l}\text { TYPE II WEIGHTS } \\
\text { Durable Goods Manufacturers }\end{array}$} \\
\hline Inventories & -0.26 & +1.20 & -0.19 & & & -0.08 \\
\hline Sales & & -1.74 & & +0.79 & +1.30 & +0.31 \\
\hline Selling prices & +0.43 & & +0.49 & +0.23 & & -0.03 \\
\hline \multicolumn{7}{|c|}{ Nondurable Goods Manufacturers } \\
\hline Inventories & +0.18 & +0.58 & +0.15 & & & -0.09 \\
\hline Sales & & -2.30 & & +2.30 & +1.02 & +0.39 \\
\hline Selling prices & +0.34 & & -0.06 & +0.87 & & -0.06 \\
\hline \multicolumn{7}{|c|}{$\begin{array}{c}\text { UNWEIGHTED } \\
\text { Durable Goods Manufacturers }\end{array}$} \\
\hline lnventories & +1.22 & -0.35 & +0.21 & & & -0.44 \\
\hline Sales & & -0.49 & & +0.30 & +0.75 & +0.28 \\
\hline Selling prices & +0.94 & & +0.22 & +0.35 & & -0.30 \\
\hline \multicolumn{7}{|c|}{ Nondurable Goods Manufacturers } \\
\hline $\begin{array}{l}\text { Inventories } \\
\text { Sales }\end{array}$ & +0.28 & $\begin{array}{l}+0.73 \\
-0.80\end{array}$ & -0.20 & +0.50 & +1.10 & $\begin{array}{l}-0.14 \\
+0.21\end{array}$ \\
\hline Selling prices & +1.01 & & +0.66 & -0.10 & & -0.45 \\
\hline
\end{tabular}

In this and the following tables the following descriptions apply: Type I Weights-a simple diffusion index was computed for each class shown in Table 1, and these were combined with weights proportional to the average percentage of firms responding in each class. The period covered was II 1953-IV 1956. Type II Weights-simple class indexes were combined with weights, proportional to the total value of net tangible assets attributable to reporting firms in each class. The period covered was II 1953-IV 1956. Unweighted - the period covered was II 1950-III 1957.

The figures in the tables have been rounded.

The equations involved in the present table are 2,3 , and 5 .

the largest manufacturers in both groups tend to show responses like those of durable goods manufacturers as a whole. But why should the acceleration coefficients be so low for the largest firms? And why should price expectations seem so generally more important, especially in sales forecasting? 
Further questions arise when we look at the coefficients based on unweighted data for a period over twice as long as that covered by the weighted data. Type I weighting produces only minor changes in diffusion data, and apart from the influence of the differing periods covered, the unweighted results should be in reasonable accord with the Type $\mathbb{I}$ results. Instead durable and nondurable goods manufacturers seem less similar in their control of inventories, more similar in their control of prices; and the contrast in acceleration coefficients is unconvincingly large. Many of the coefficients are probably not statistically significant, given the few degrees of freedom on which the estimates must be based. Nevertheless, a more stable pattern of results seems a reasonable requirement on the basis of earlier work with diffusion data. ${ }^{8}$

Recursive Model. The recursive model of manufacturers' expectations affords an opportunity to test many of these reactions. Table 3 is based on the independent application of least squares to each equation separately, Table 4 on a sequential application of least squares in which current values of the explanatory variables in each equation are computed from the prior equation or equations in the recursive chain. The latter process begins with the direct application of least squares to the price equation, which depends only on lagged values of explanatory variables; so that the coefficients of this equation in each section of Table 3 are identical with the coefficients of the equation in the corresponding sections of Table 4 . Both tables also show the estimated standard errors of the several coeffcients (in parentheses), together with standard errors of estimate and coefficients of multiple correlation adjusted for degrees of freedom. These measures provide crude indications of the statistical significance of the estimated equations, but neither the assumptions of the model nor the number of quarters covered justify the application of exact tests.

Since the model embodies a different theory of expectation formation than the exactly identified one, it naturally yields different findings even about the formation of inventory intentions (Table 3). Thus we note no marked contrast between the models for durable and nondurable goods manufacturers, or even between models based on Type $\mathbb{I}$ and Type II weighting. The larger firms again have lower Type II acceleration coefficients, and their sales anticipations give less weight to new orders and lagged sales. However, new order diffusion and sales diffusion show similar variations over time, implying that their estimated coefficients in the equations for sales anticipations have low precision (note the standard errors in the first two sections of Table 3).

The pattern of Type $\mathbb{I}$ results is borne out by the unweighted results, except for the suggestion that inventory control was less complete over the longer period-a finding compatible with our knowledge of inventory behavior during the Korean war. The evidence of collinearity between new

8 Hastay, pp. 93-123. 
EXPECTATIONS ABOUT OPERATING VARIABLES

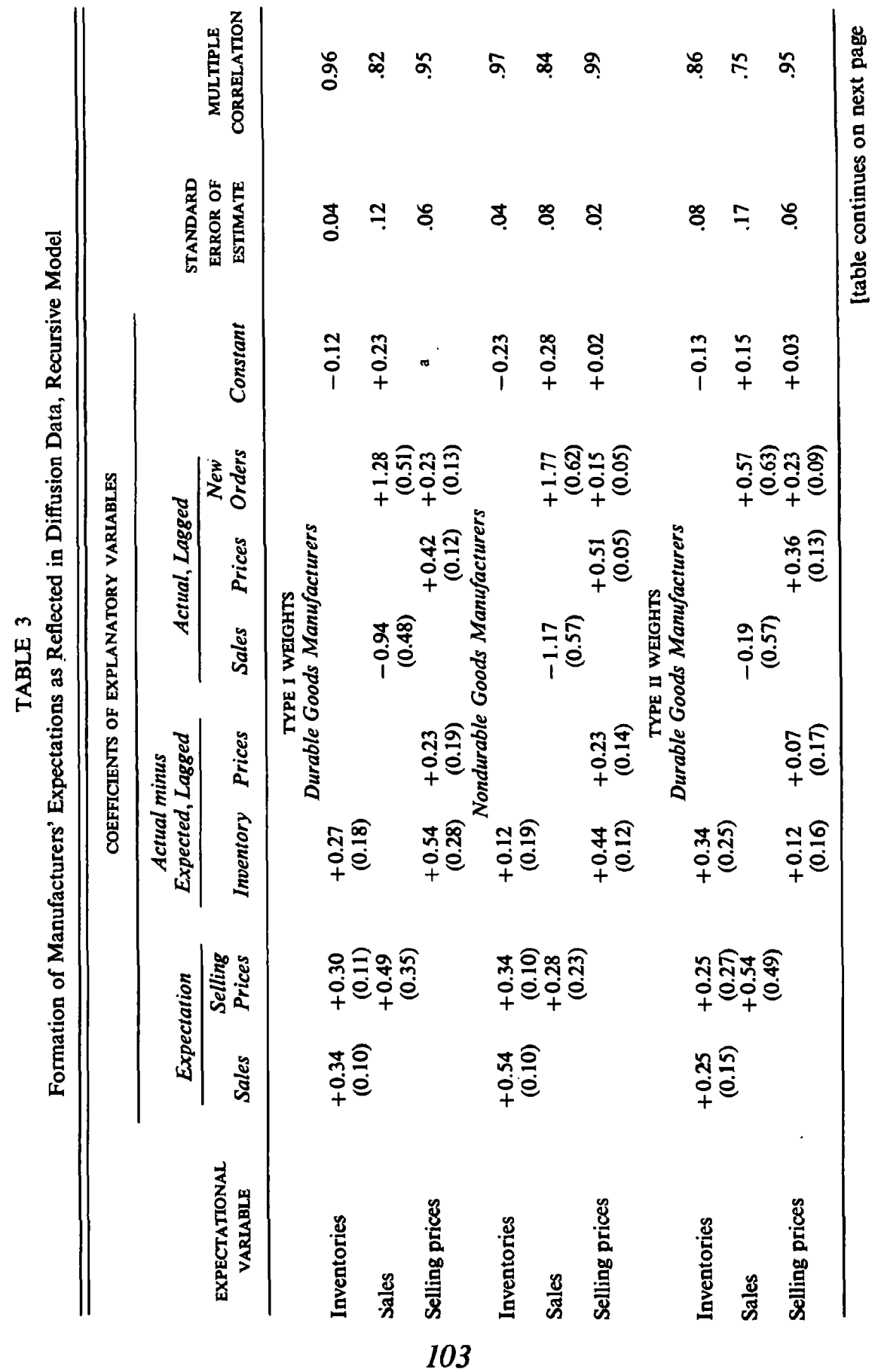




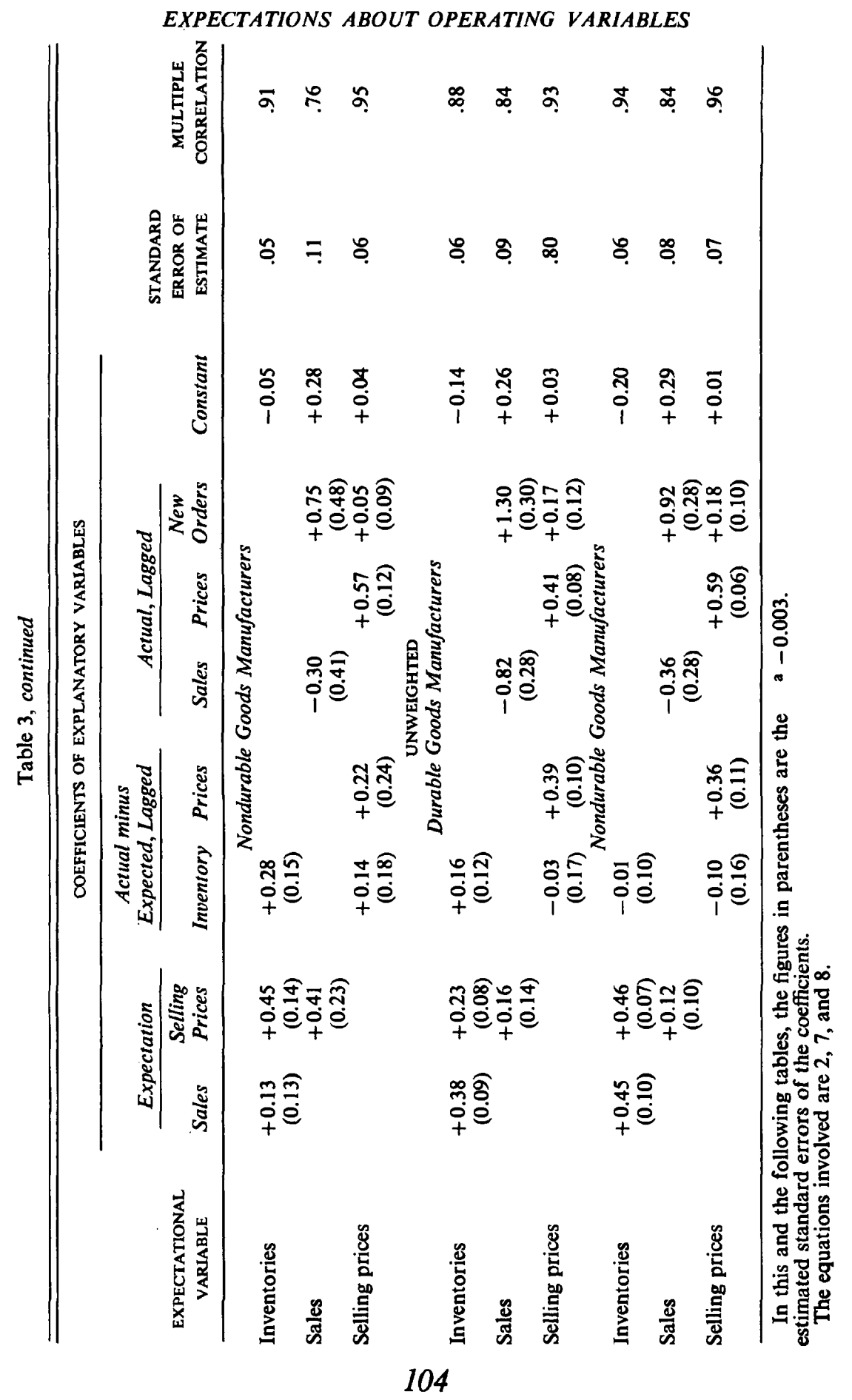


EXPECTATIONS ABOUT OPERATING VARIABLES

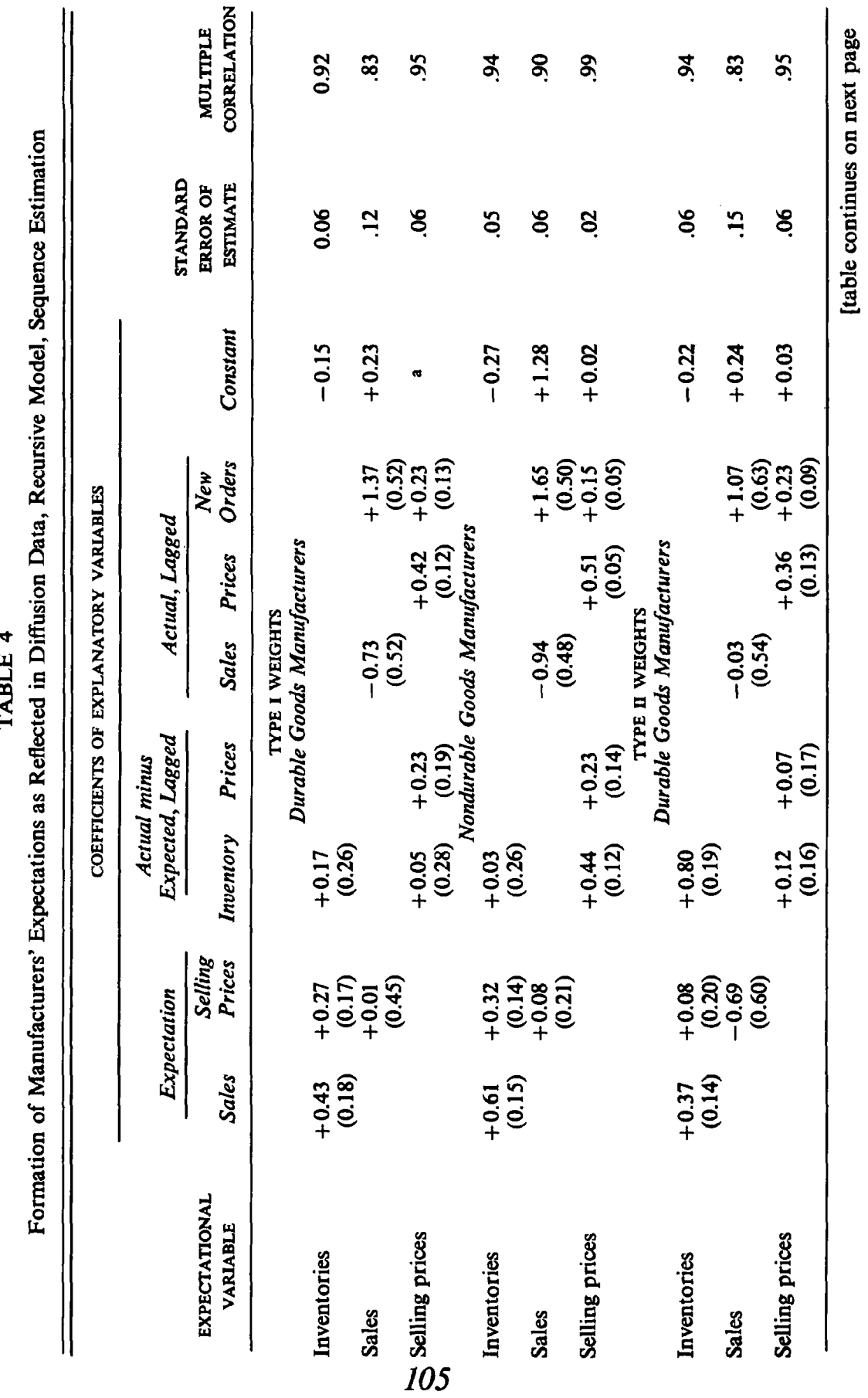


EXPECTATIONS ABOUT OPERATING VARIABLES

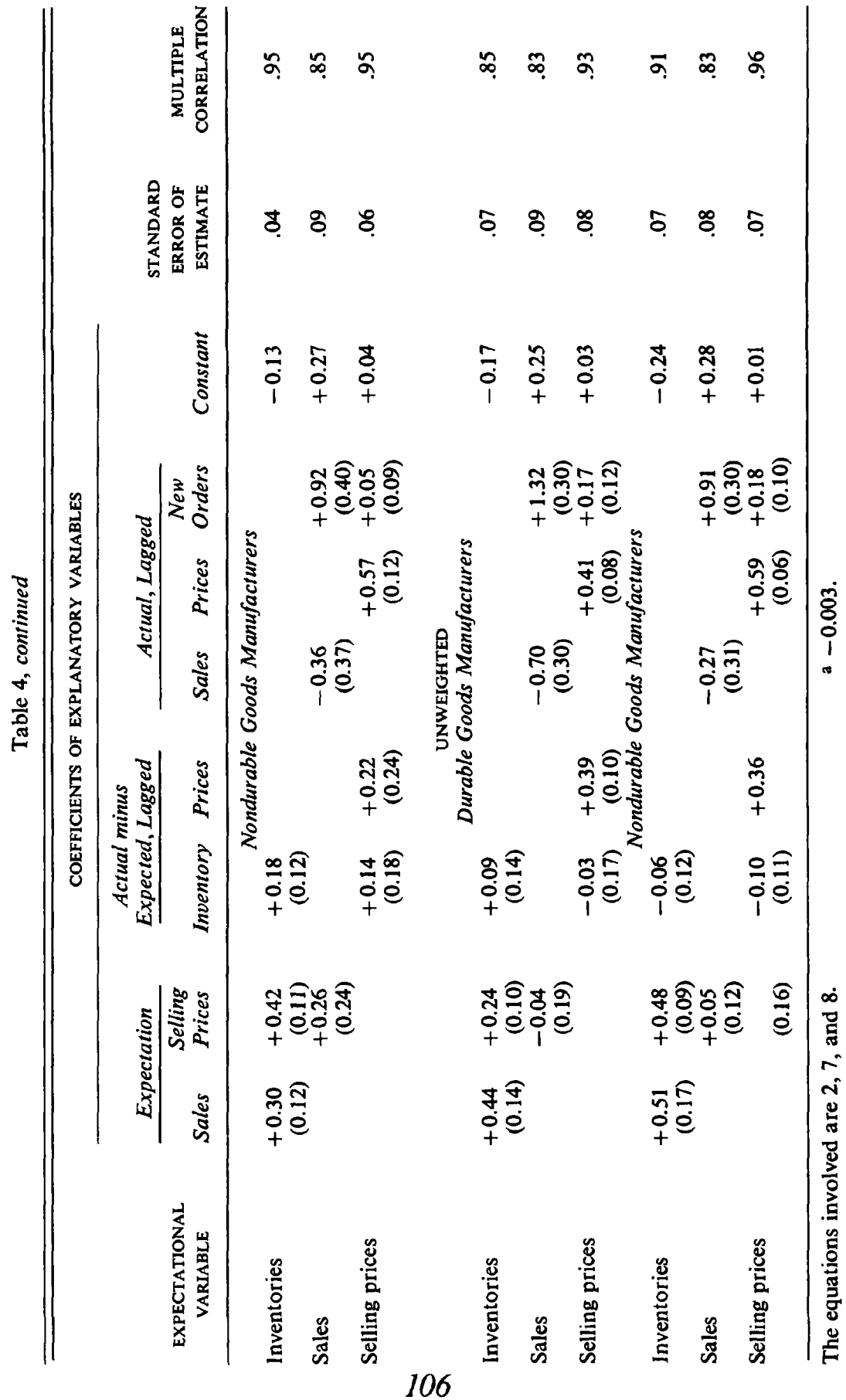




\section{EXPECTATIONS ABOUT OPERATING VARIABLES}

order diffusion and sales diffusion is not so marked in the unweighted coefficients, so that the generally strong influence of current new order experience on sales anticipations suggested by the Type I data is confirmed.

Table 4 provides a check of the pattern of findings in Table 3 , based on a technique of estimation that involves less stringent assumptions about the stochastic properties of the recursive model. In particular, the disturbances $u_{1}$ in the several equations need not be regarded as uncorrelated within a given time period. Under these more realistic conditions the estimates will still be "consistent," but replacing current explanatory variables by their predicted values in the estimation process may enhance the collinearity of the revised set of explanatory series and reduce the stability of the estimated coefficients. However the results summarized in Table 4 broadly agree with those in Table 3. Only the following differences are noteworthy:

1. Current new orders are more important in shaping the sales anticipations of the largest firms.

2. The role of selling-price expectations in shaping sales anticipations is substantially reduced.

3. The weighted data are less clear-cut on the respective roles of sellingprice expectations and inventory maladjustments in shaping inventory intentions.

The second point may reflect only the collinearity of predicted selling-price expectations with realized new orders, and the third only the similar collinearity of such expectations with the measure of inventory maladjustments, although there is no marked increase in standard errors such as would be implied by enhanced collinearity.

The pattern of results found in Tables 3 and 4 is fully interpretable in terms of the recursive model of expectation formation provided we infer (1) that inventory accumulation seldom moves in an undesired direction for as long as two quarters, and (2) that prices, where they are an instrument of deliberate control, are at least equally adaptable to the evolving estimates of market strength. By the test of multiple correlation coefficients, sales anticipations are least successfully explained by the model, price expectations most successfully explained, and inventory intentions only slightly less successfully explained. Except for sales anticipations, the explanations are uniformly more successful than are explanations provided by a scheme of direct extrapolation. ${ }^{9}$ The advantage is greatest for inventory intentions.

Charts 1 and 2 exhibit the predictive ability of the models presented in the Type I weighting results in Table 3. The two top curves in each figure represent expected diffusion as actually reported in the Dun and Bradstreet surveys, $b(\bar{X})$, and the corresponding predictions of expected diffusion

9 Compare Hastay, p. 118. 


\section{EXPECTATIONS ABOUT OPERATING VARIABLES}

based on the equation under consideration, $b^{\prime}(\bar{X})$. The remaining curves represent the contributions of the various explanatory variables to the

CHART 1

Durable Goods Manufacturers, Expected Diffusion, Recursive Model
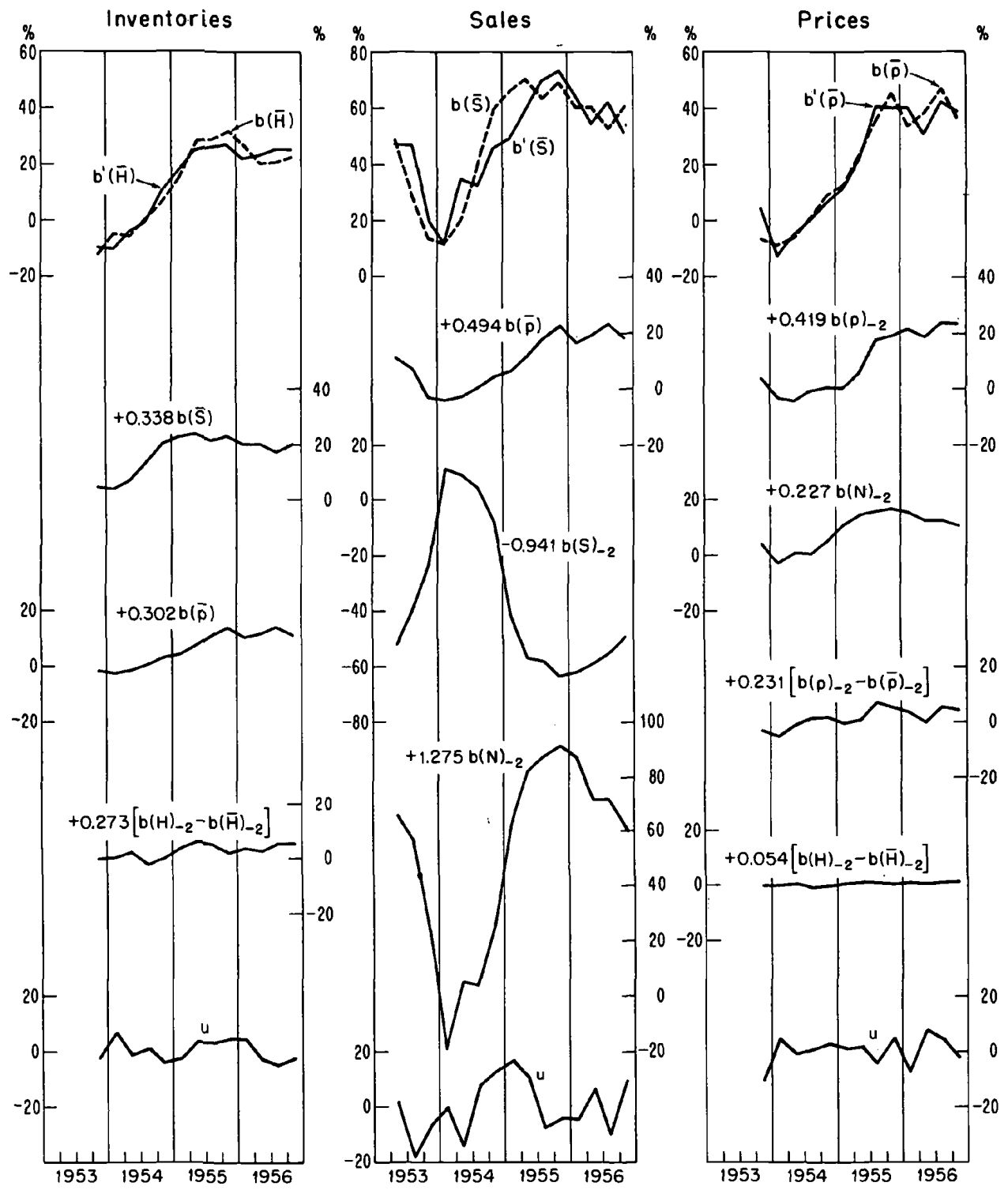

predicted series, together with the divergence of the actual from the predicted series.

Methodological Implications. The rather unfavorable showing of the 
EXPECTATIONS ABOUT OPERATING VARIABLES

simultaneous-equation model of expectation formation appears to have methodological, as much as substantive, implications. Because the model

CHART 2

Nondurable Goods Manufacturers, Expected Diffusion, Recursive Model

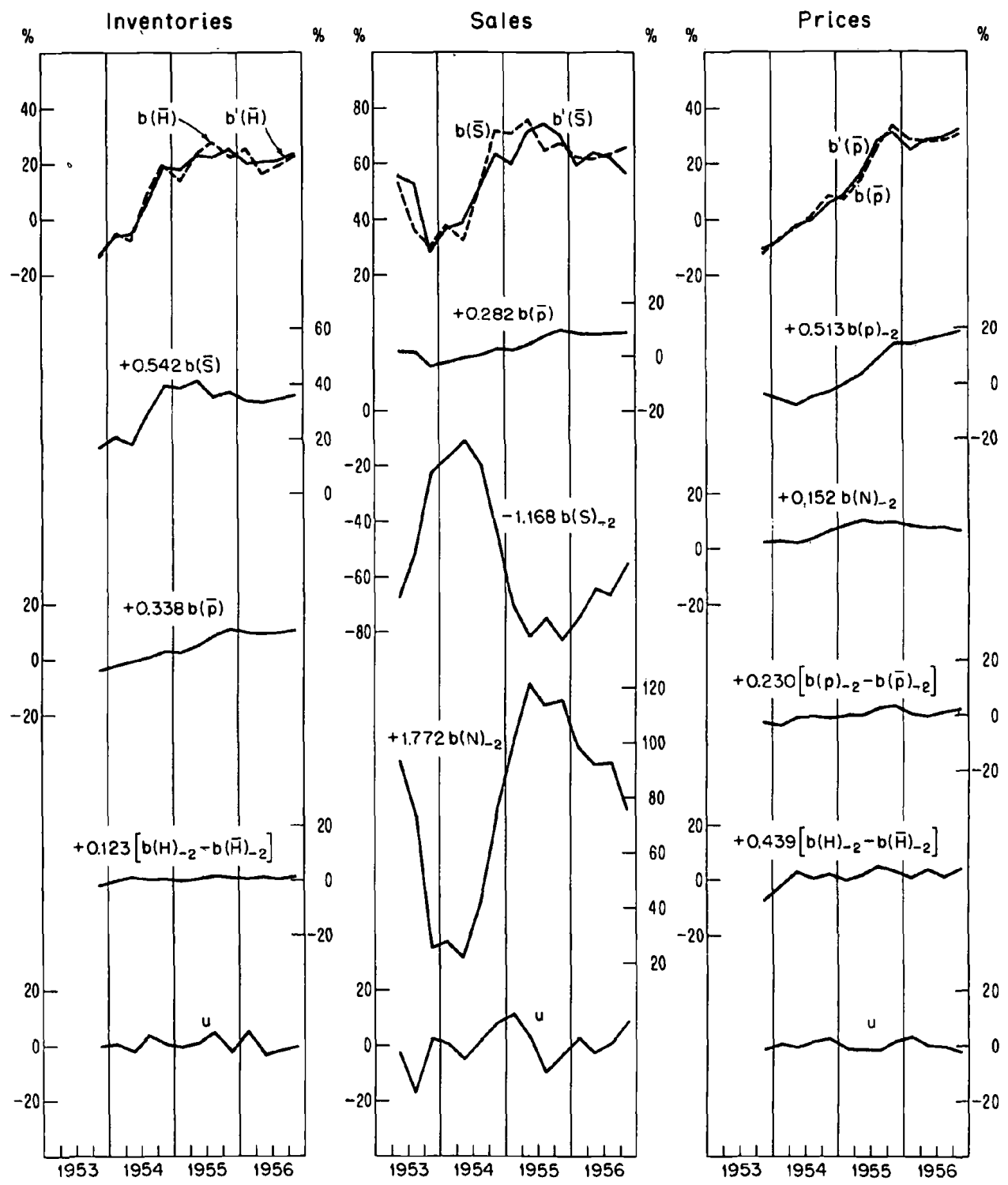

is exactly identified, it can be evaluated by the technique of indirect least squares. In practice, this means that each of the endogenous variables-sales anticipations, price expectations, and inventory intentions- 
is independently regressed on all three of the lagged variables of the model. The coefficients in these auxiliary regression equations are unique functions of the unknown coefficients of the model, sufficient in number to permit of an exact solution for the model coefficients. But the solution depends practically on the identifiability of the model being "strong" enough so that sampling variability of the regression coefficients does not cause them to take on values characteristic of the regression coefficients of underidentified models.

The instability in the computed coefficients for our simultaneousequation model may thus have one or more sources:

1. The modeis may not be strongly identified. This explanation seems unlikely, as direct examination of the identification question does not suggest that the identifiability of the model is sensitive to the numerical values of the unknown coefficients for quite wide ranges of possible variation.

2. The regression coefficients determined in the first round of the indirect least-squares technique may be subject to wide sampling variability. This explanation holds for the Type II weighting results in Table 2, where there are only 10 degrees of freedom, but applies with less force to the unweighted results where 27 degrees of freedom exist. $\mathbb{A}$ factor here may be that the diffusion data, being based on samples, are subject to measurement errors which add to the sampling variability of the regression coefficients without showing up in the computed standard errors. This explanation must therefore be classed as possible.

3. Collinearity among the endogenous variables may be the source of coefficient instability. The collinearity is notably high between sales anticipations and price expectations in every industrial group, and is fairly high even between these variables and inventory intentions. The third explanation therefore seems the most important one in accounting for the instability of the findings on the nonrecursive model of manufacturers' expectations. Combined with the possible influence of the second explanation, it seems to rule out any practicable test of the model until the supply of statistical data is expanded or the precision of the diffusion estimates can be improved.

\section{TRADERS' EXPECTATIONS}

The traders' model of expectation formation, being recursive, presents no new statistical problems. It embodies, however, a different theory of expectations. Because the typical trader is imagined to have no effective control over prices, future sales rather than future prices are assumed to mark the first stage in his forward thinking. He predicts that sales will continue to change about as they did in the previous period, adjusting for any mistake in his last prediction. He next forecasts the change in selling 


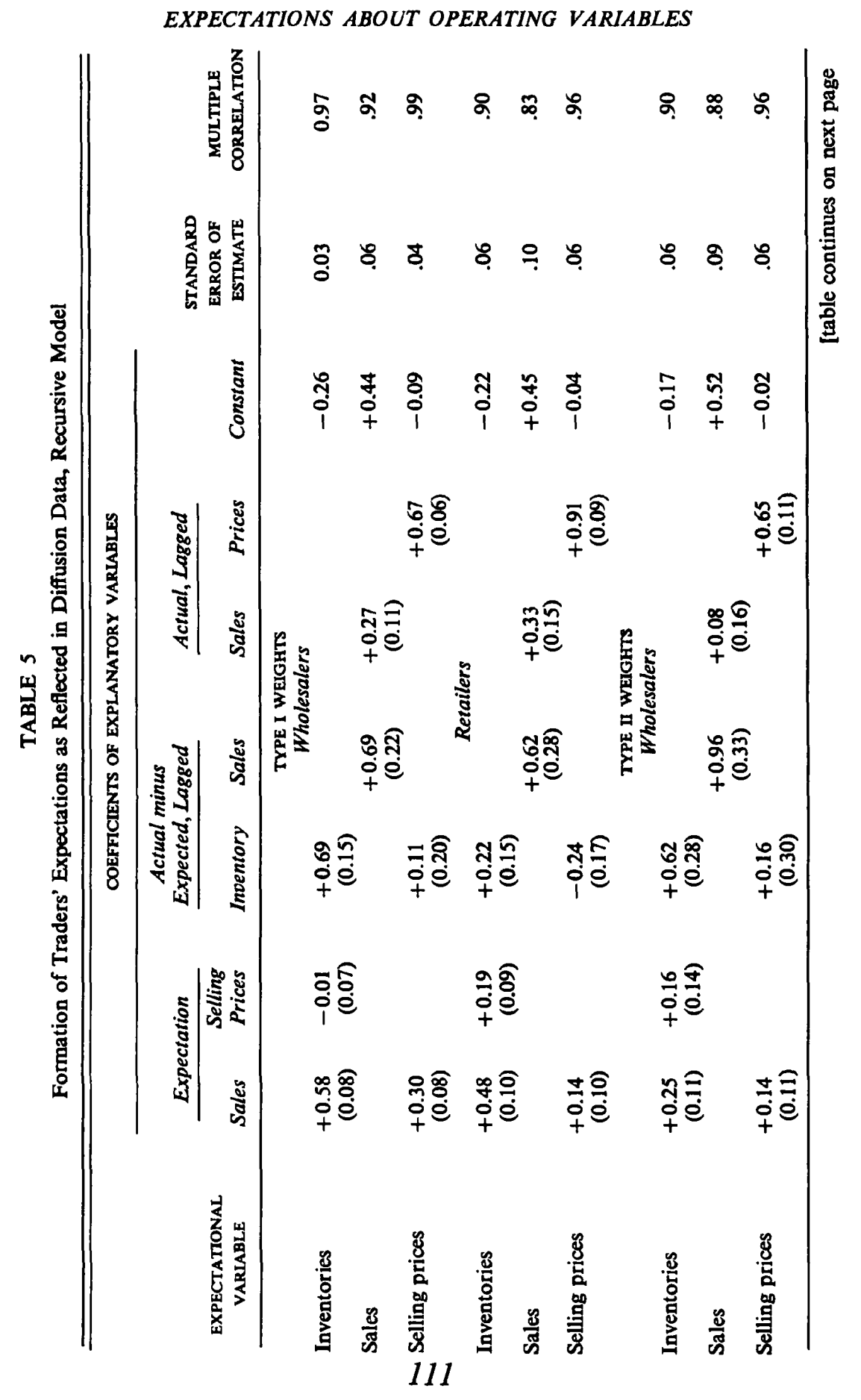


EXPECTATIONS ABOUT OPERATING VARIABLES

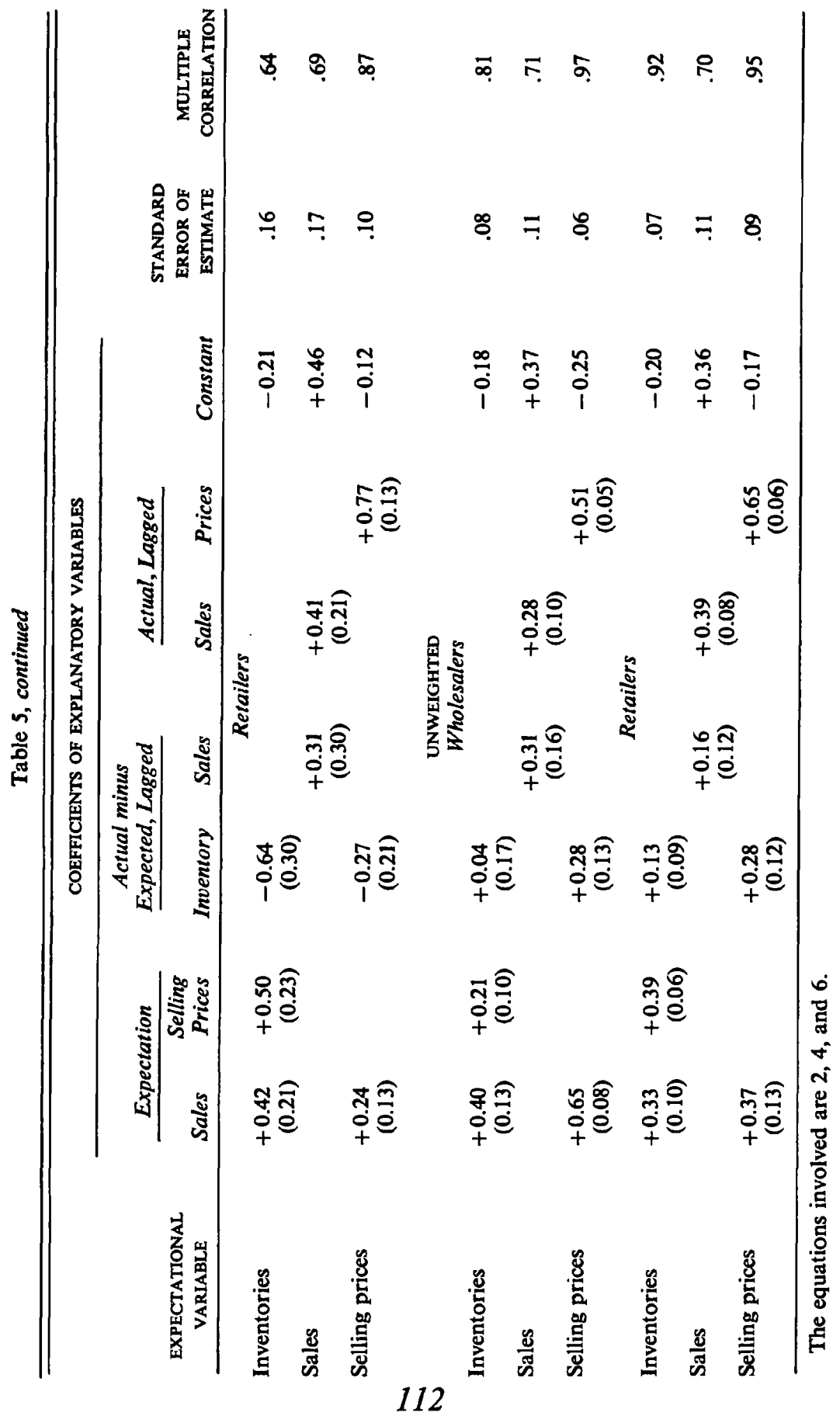


EXPECTATIONS ABOUT OPERATING VARIABLES

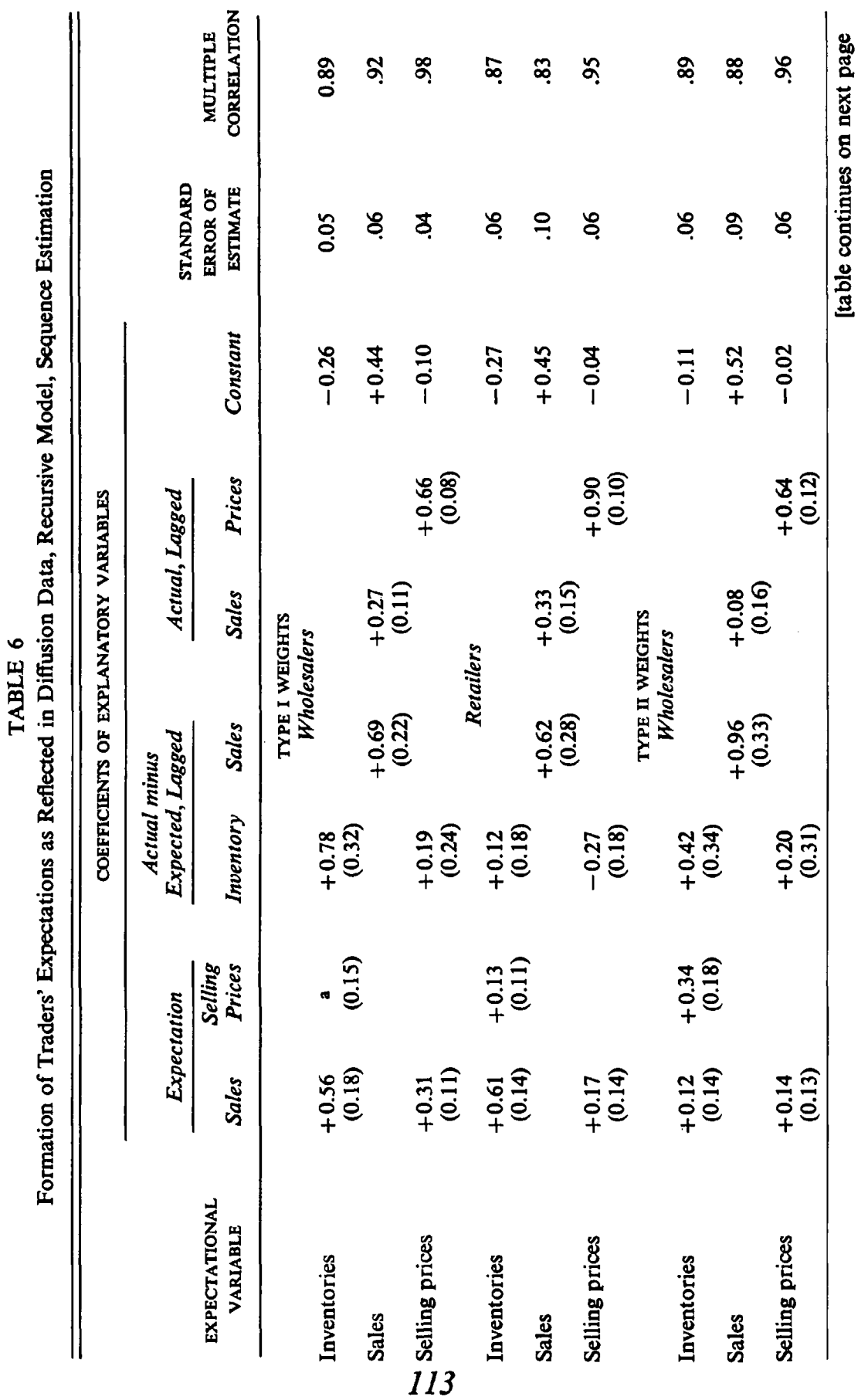




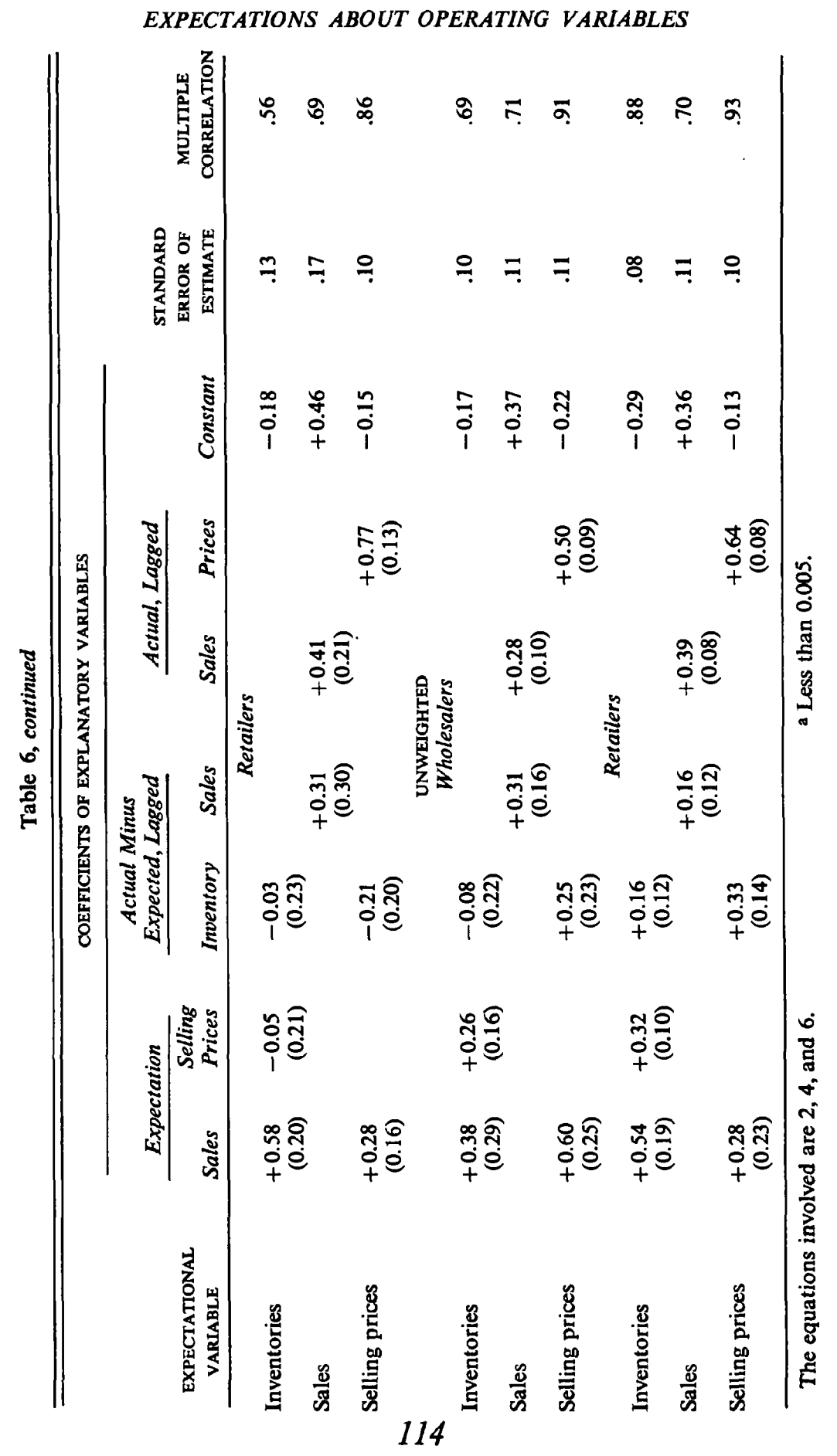


prices by projecting conservatively the recent trend of prices, estimating the effect of the already predicted trend of sales, and making allowance for any disequilibrium in his current inventory position. Finally, he sets his inventory-investment objective on the basis of his sales and price forecasts and his appraisal of his current inventory position. Tables 5 and 6 summarize the results of fitting this model to diffusion data for wholesalers and retailers in a form parallel to Tables 3 and 4.

Thus Table 5 is based on the independent application of least squares to each equation separately. As in the case of manufacturers, few coefficients seem puzzling in the light of the model tested, except perhaps the two coefficients of the inventory-appraisal variable in the retailers' model (Type I weighting) which offer contradictory evidence on the flexibility of inventory accumulation. But then the largest retailers show consistent evidence of having less effective control over inventories than do retailers as a whole (compare the Type II data with the other two sets). Speaking generally, the sizes of coefficients, relative to their standard errors, attest to the genuine influence of all the factors embraced by the model. However, inventory appraisal may have little influence on the price expectations of both classes of traders and, for wholesalers, selling-price expectations little influence on inventory objectives. The influence of the period studied can be seen in the unweighted results, where the reduced effect of stock appraisal on the inventory intentions of wholesalers may be traceable to the Korean war period.

Table 6 is based on a sequential application of least squares. Though an increase in standard errors pushes several coefficients into the doubtfully significant class, the pattern of results closely parallels that of Table 5, except for less contrast between large wholesalers and large retailers in their control over short-run inventory accumulation (compare the Type II results).

Charts 3 and 4 show the predictive ability of the traders' models based on Type I weighted data. They bear out the testimony of the multiple correlation coefficients, that price expectations are most successfully explained and sales anticipations least successfully explained by the models. As in manufacturing, except for sales anticipations, the models are superior to explanations of expected diffusion based on extrapolation, and the advantage is greatest for inventory intentions. ${ }^{10}$

\section{Refinements of the Expectations Models}

Several features of the models so far discussed are less than satisfactory. The dependence of inventory planning on buying prices has been omitted from the statistical work, and the distinction between manufacturers' stocks of purchased materials and their stocks of finished goods has not

10 Hastay, op. cit. 


\section{EXPECTATIONS ABOUT OPERATING VARIABLES}

been explicitly recognized. Also, the measures of ex post disequilibria of inventories and selling pricês are tọo crude to yield confident insight into

\section{CHART 3}

Wholesale Traders, Expected Diffusion, Recursive Model without Buying Prices

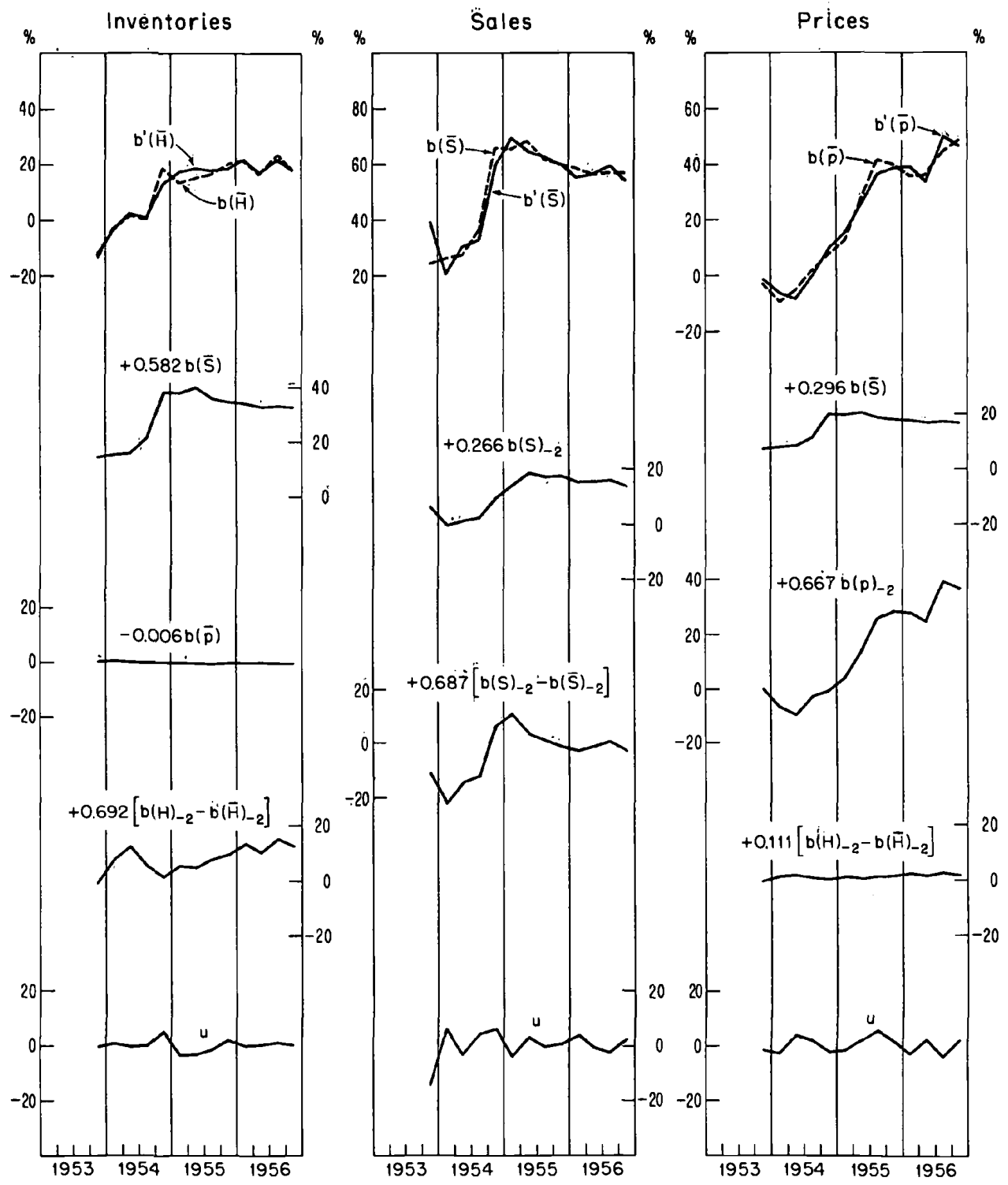

the role of this factor in planning. Now we will consider several experiments designed to remedy these shortcomings. 


\section{EXPECTATIONS ABOUT OPERATING VARIABLES}

THE REFINEMENTS

Buying-Price Expectations. The role of buying-price expectations can be investigated only for the traders' model, using the selling-price diffusion

CHART 4

Retail Traders, Expected Diffusion, Recursive Model without Buying Prices

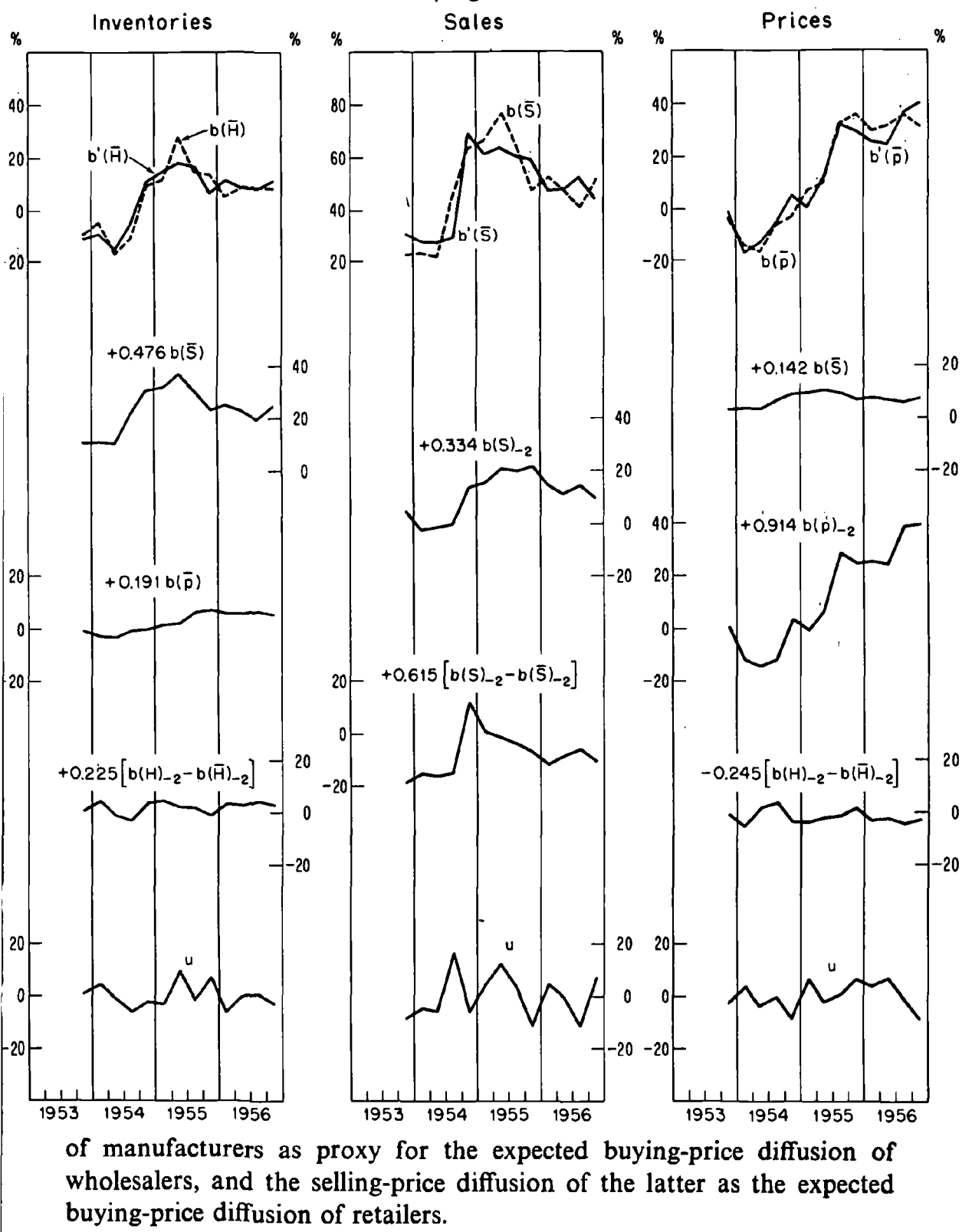


Since firms are not acquainted with the expectations of their suppliers, the most recent diffusion of actual selling prices of the earlier processors are taken as the expected buying-price diffusion. In symbols, $b\left(p_{h}\right)_{-2}$ serves as proxy for $b\left(\overline{p_{h}}\right)$. Restated in terms of this proxy, the general inventory equation for traders becomes:

$$
b(\bar{H})=a_{1} b(\bar{S})+a_{2} b(\bar{p})+a_{3} b\left(p_{h}\right)_{-2}+a_{4}\left[b(H)_{-2}-b(\bar{H})_{-2}\right]+a_{0}+u_{1}
$$

Expected buying prices affect not only inventory intentions but also sales and price anticipations. The nature of the influence on sales anticipations is uncertain. A rise in expected buying prices should depress sales anticipations. But since price rises are frequently associated with improved business, the final impact may be negligible or even positive. On sellingprice anticipations, however, the influence should be predominantly positive. Thus the traders' model, expanded to allow for buying-price expectations, takes the form:

$$
\begin{aligned}
& b(\bar{H})=a_{1} b(\bar{S})+a_{2} b(\bar{p})+a_{3} b\left(p_{h}\right)_{-2}+a_{4}\left[b(H)_{-2}-b(\bar{H})_{-2}\right]+a_{0}+u_{1} \\
& b(\bar{S})=c_{1} b(S)_{-2}+c_{2}\left[b(S)_{-2}-b(\bar{S})_{-2}\right]+c_{3} b\left(p_{h}\right)_{-2}+c_{0}+u_{3} \\
& b(\bar{p})=g_{1} b(\bar{S})+g_{2} b(p)_{-2}+g_{3} b\left(p_{h}\right)_{-2}+g_{4}\left[b(H)_{-2}-b(\bar{H})_{-2}\right]+g_{0}+u_{5}
\end{aligned}
$$

Although the realized diffusion index $b\left(p_{h}\right)_{-2}$ figures as a measure of expectations in this model, it is a predetermined variable with respect to its statistical properties and does not require explanation within the model. Thus the number of explanatory equations remains three.

Manufacturers' Purchased Materials. The Dun and Bradstreet questionnaire does not plainly call for inventories of finished goods. Moreover, running in dollar terms, the responses may well include purchased materials. Fortunately, there is evidence to suggest that the acquisition of purchased materials tends to follow new orders with a lag that depends on average delivery time. The lag is probably less than two quarters, but in view of the close association of expected sales and expected new orders in the Dun and Bradstreet reports, the relation is expressed in terms of the diffusion of realized new orders, $b(N)_{-2}$. The resulting equation for manufacturers' inventory intentions takes the form:

$$
b(\bar{H})=a_{1} b(\bar{S})+a_{2} b(\bar{p})+a_{3} b(N)_{-2}+a_{4}\left[b(H)_{-2}-b(\bar{H})_{-2}\right]+a_{0}+u_{1}
$$

Since $b(N)_{-2}$ is a predetermined variable within the model, the remaining equations of the manufacturers' model are unaltered.

Ex post Disequilibria. Because of decisions based on erroneous expectations, businessmen often find that matters under their control, such as inventories and selling price, are not in appropriate adjustment to their current environment. Decisions for the future must take account of such maladjustments. So far they have been measured as the difference between attained positions at a given time, $b(\mathbb{X})$, and the corresponding positions 
expected or planned two quarters earlier, $b(\bar{X})$. But this approach would be fully appropriate only if the planning period were two quarters (i.e. only if decisions taken were not subject to review or modification before two quarters had elapsed). However, nearly all the results suggest that the planning period is typically shorter, for the coefficients of the disequilibrium measures are usually positive, as might be expected if departures of attained positions $b(X)$ from prior intended positions $b(\bar{X})$ were typically in the direction deemed appropriate in the light of revisions of expectations during the two quarter period.

The problem, therefore, is to express the fact that, at the planning date, equilibrium positions of the instrument variables, $b(\hat{X})$, generally differ from the positions expected two quarters earlier, $b(\bar{X})$. In this proposed notation, measures $[b(X)-b(\bar{X})]$ representing divergence from expectations are to be replaced with measures of divergence from equilibrium $[b(X)-b(X)]$.

Now, it seems probable that planned reactions to uncertain expectations will differ from the reactions that would be planned if the same data were known with ex post accuracy. In general, the coefficients expressing planned reactions should be smaller than those expressing the reactions deemed appropriate to the same data by hindsight. Let us call an equation expressing planned reactions to uncertain data the "planning function," the corresponding equation expressing "retrospective" reactions the "equilibrium function." (The kind of equilibrium implied is of course dynamic.) The equations should have the same form and, to the degree that they depend on retrospective data, the same coefficients. To illustrate these ideas in connection with inventory planning by manufacturers, we have for the planning function:

$$
b(\bar{H})=a_{0}+a_{1} b(\bar{S})+a_{2} b(\bar{p})+a_{3} b(N)_{-2}+a_{4}\left[b(H)_{-2}-b(\hat{H})_{-2}\right]+u_{1}
$$

and for the equilibrium function:

$$
b(A)=a_{0}+\hat{a}_{1} b(S)+\hat{a}_{2} b(p)+\hat{a}_{3} b(N)+a_{4}\left[b(H)_{-2}-b(A)_{-2}\right]+v_{1}
$$

Use of the identity $b(H)-b(A)=[b(H)-b(\bar{H})]-[b(A)-b(\bar{H})]$ now easily establishes as the definition of attained disequilibrium for inventories:

$$
\begin{aligned}
b(H)_{-2}-b(\hat{H})_{-2}= & {\left[b(H)_{-2}-b(\bar{H})_{-2}\right]-\hat{a}_{1}\left[b(S)_{-2}-b(\bar{S})_{-2}\right] } \\
& -\hat{a}_{2}\left[b(p)_{-2}-b(\bar{p})_{-2}\right]-\hat{a}_{3}\left[b(N)_{-2}-b(N)_{-4}\right] \\
& -\left(\hat{a}_{1}-a_{1}\right) b(\bar{S})_{-2}-\left(\hat{a}_{2}-a_{2}\right) b(\bar{p})_{-2} \\
& -\left(\hat{a}_{3}-a_{3}\right) b(N)_{-4}
\end{aligned}
$$

An obvious substitution of $b\left(p_{h}\right)$ for $b(N)$ yields a corresponding result for attained disequilibrium in the traders' model that includes buying prices. Alternatively, elimination of the terms in $b(N)$ establishes the form of the definition for the simpler version of inventory planning with new orders and buying prices absent. 
Since prices are also treated as instrument variables in the manufacturers' models, we require corresponding measures of attained price disequilibrium. An exactly parallel argument yields the formulas:

$$
\begin{aligned}
b(p)_{-2}-b(\hat{p})_{-2}= & {\left[b(p)_{-2}-b(\bar{p})_{-2}\right]-\hat{d}_{1}\left[b(S)_{-2}-b(\bar{S})_{-2}\right] } \\
& -\left(\hat{d}_{1}-d_{1}\right) b(\bar{S})_{-2}
\end{aligned}
$$

in the exactly identified, nonrecursive model, and:

in the recursive model.

$$
\begin{aligned}
b(p)_{-2}-b(\hat{p})_{-2}= & {\left[b(p)_{-2}-b(\bar{p})_{-2}\right]-\hat{d}_{2}\left[b(N)_{-2}-b(N)_{-4}\right] } \\
& -\left(\hat{d}_{2}-d_{2}\right) b(N)_{-4}
\end{aligned}
$$

The refinement of the models of expectation formation envisaged here can now be accomplished by substituting for the formal definitions of attained disequilibria $\left[b(X)_{-2}-b(\hat{X})_{-2}\right]$ the operational measures worked out above, in which the parameters $\hat{a}$ and $\hat{d}$ become unknowns to be estimated from the data. The substitutions are required only for instrument variables since the problem arises only in connection with variables over which the firm is assumed to have direct control. It follows that in all models the difference $\left[b(S)_{-2}-b(\bar{S})_{-2}\right]$ will remain unaltered, as will the difference $\left[b(p)_{-2}-b(\bar{p})_{-2}\right]$ in the model of traders' expectations.

As subjected to statistical test in the following section, the definitions of attained disequilibria are somewhat truncated by the omission of the correction terms in lagged expectations: $\left(\hat{a}_{1}-a_{1}\right) b(\bar{S})_{-2},\left(\hat{a}_{2}-a_{2}\right) b(\bar{p})_{-2}$, $\left(\hat{d}_{2}-d_{2}\right) b(N)_{-4}$, and so forth. The omission is necessary to conserve degrees of freedom by cutting down on the number of predetermined variables in the various models. The resulting measures of disequilibria are thus only approximations, but they suffice for a rough check of the logic of the refinement. ${ }^{11}$

\section{STATISTICAL EFFECTS OF THE REFINEMENTS}

The first refinement can be studied only for traders, the second applies only to manufacturers, while the third applies to both. For traders, the first and third refinements are discussed separately, then together; for manufacturers, the third refinement is taken up separately, but the second only with the third. The statistical examination is therefore not logically complete for manufacturers, but it need not be. It is made so for traders only to be sure of isolating the effect of buying prices on expectations, since we need to gauge the consequences of omitting such prices from the manufacturers' models.

Traders' Buying Prices. The first model under examination is defined by equations 10,11 , and 12 . Table 7 shows the results of fitting the model to the weighted and unweighted diffusion data. The method of singleequation least squares was used to estimate all the coefficients.

11 See, however, the reservation expressed on page 129. 
EXPECTATIONS ABOUT OPERATING VARIABLES

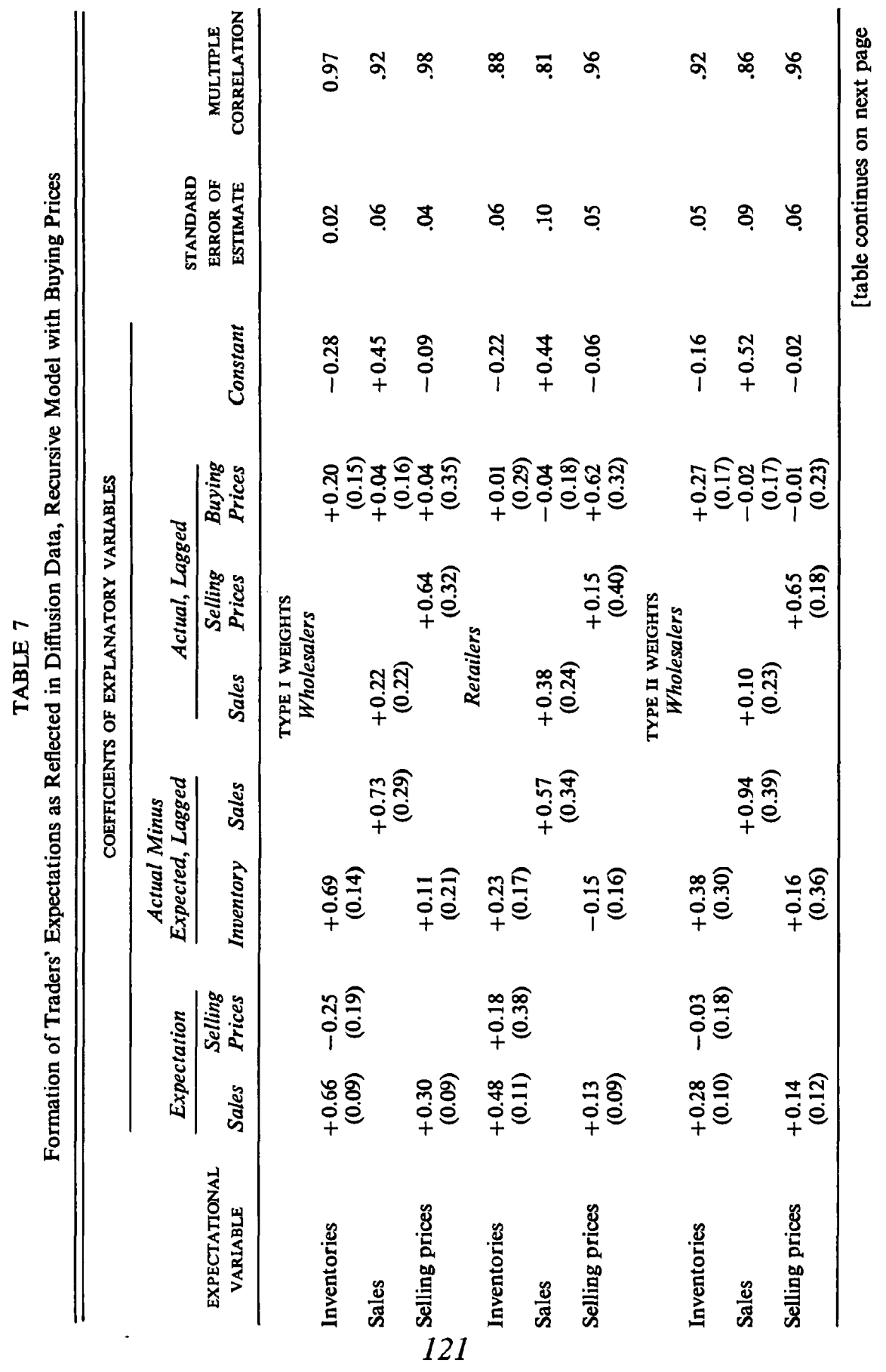




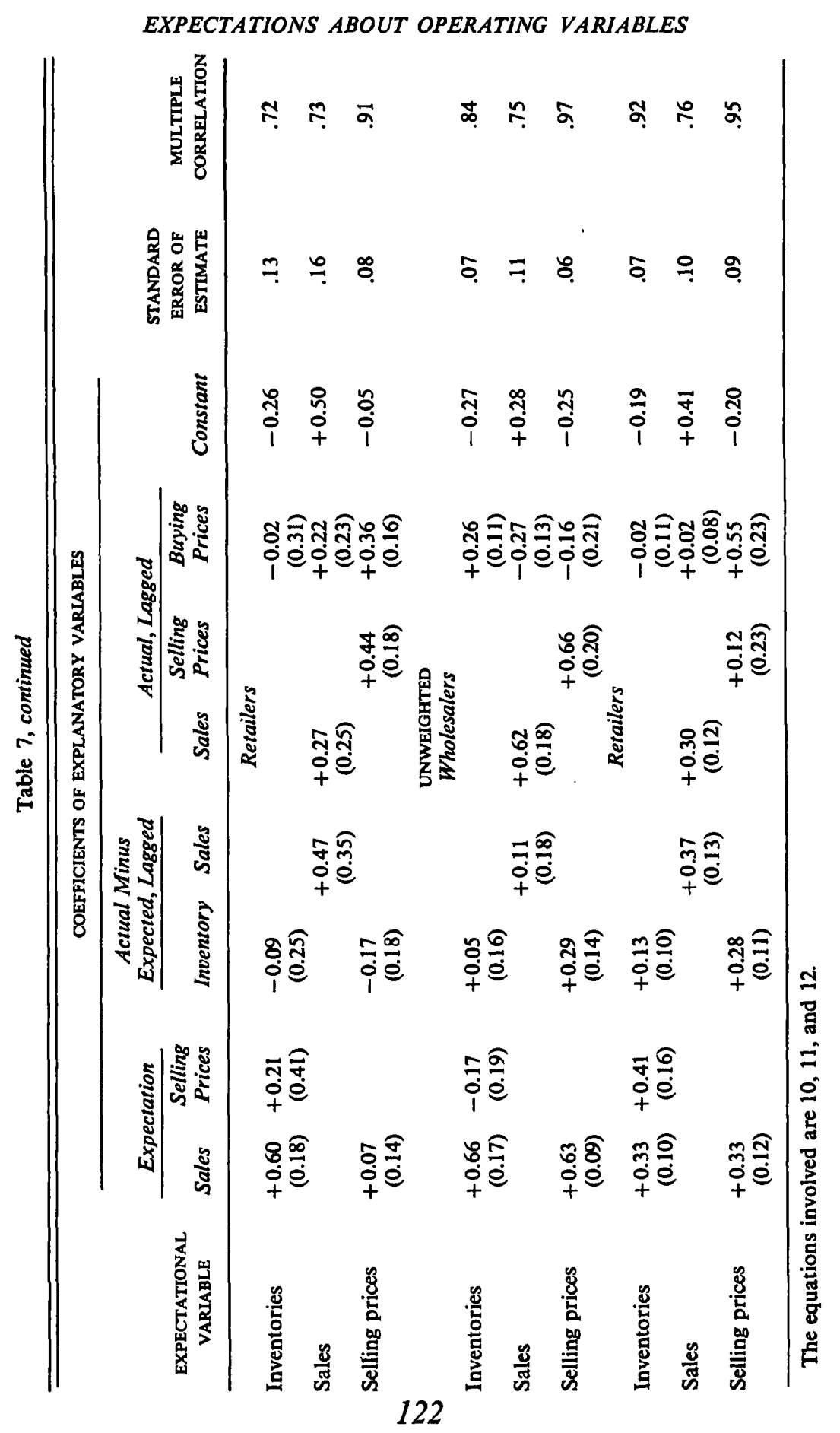


By the test of multiple correlation coefficients, the introduction of buying-price diffusion produces little change in the traders' models. There is no improvement for models fitted to weighted data of Type I, improvement only in the case of retailers for models fitted to weighted data of Type II, and but slight improvement for models fitted to unweighted data (compare Tables 5 and 7). For buying-price coefficients, however, the case is less clear. The coefficients are generally negligible, but they are of material size and possibly significant in the equations for retailers' sellingprice anticipations and wholesalers' inventory intentions. The equations for retailers' sales anticipations (Type II weighted data) and wholesalers' sales and price anticipations (unweighted data) also show substantial coefficients, but the exceptions are probably too unsystematic to argue for a clear influence of buying prices on sales anticipations in general or on wholesalers' price anticipations in particular.

Some insight into this conflict of testimony is gained by examining the effect of buying prices in the two groups of equations where they seem important. Consider, first, the equations for selling-price anticipations, equation 12. To a good approximation, the coefficients of realized buyingprice diffusion and realized selling-price diffusion in the expanded equations sum to the value of the realized selling-price coefficient alone in the original equations without buying prices, equation 6 . This sum of coefficients is not quite large enough in the retailers' models applied to weighted data, but the rule holds for wholesalers in all cases and for retailers in the model applied to unweighted data. Moreover, though the buying-price coefficient is frequently small, both coefficients have substantially larger standard errors in the expanded models. These facts attest to the close correspondence of realized selling prices and realized buying prices in trade, and suggest why an apparently significant expectational variable can have so little explanatory value in a model that already includes realized selling prices.

Consider, next, the equations for inventory intentions, equations 10 and 2. Comparison of Table 7 with Table 5 discloses a strong tendency for the influence of selling-price anticipations to be reduced when realized buying prices are taken into account, strong enough to produce negative values for the coefficient of anticipated selling prices in every wholesalers' model. It also produces small to substantial reductions in the same coefficient in the retailers' models applied to weighted data, though the model applied to unweighted data provides an exception. The explanation appears to lie in the marked collinearity of realized buying prices and expected selling prices. Because of this collinearity, the change in the coefficient of anticipated selling prices tends to be offset by the coefficient of realized buying prices, the sum of the coefficients being of the order of the single coefficient of anticipated selling prices in the inventory equation having no buying-price variable. The rule holds quite well for models 


\section{EXPECTATIONS ABOUT OPERATING VARIABLES}

fitted to weighted data of Type I and to unweighted data, especially for retailers; but it holds poorly or not at all for models fitted to weighted data

CHART 5

Wholesale Traders, Expected Diffusion, Recursive Model with Buying Prices

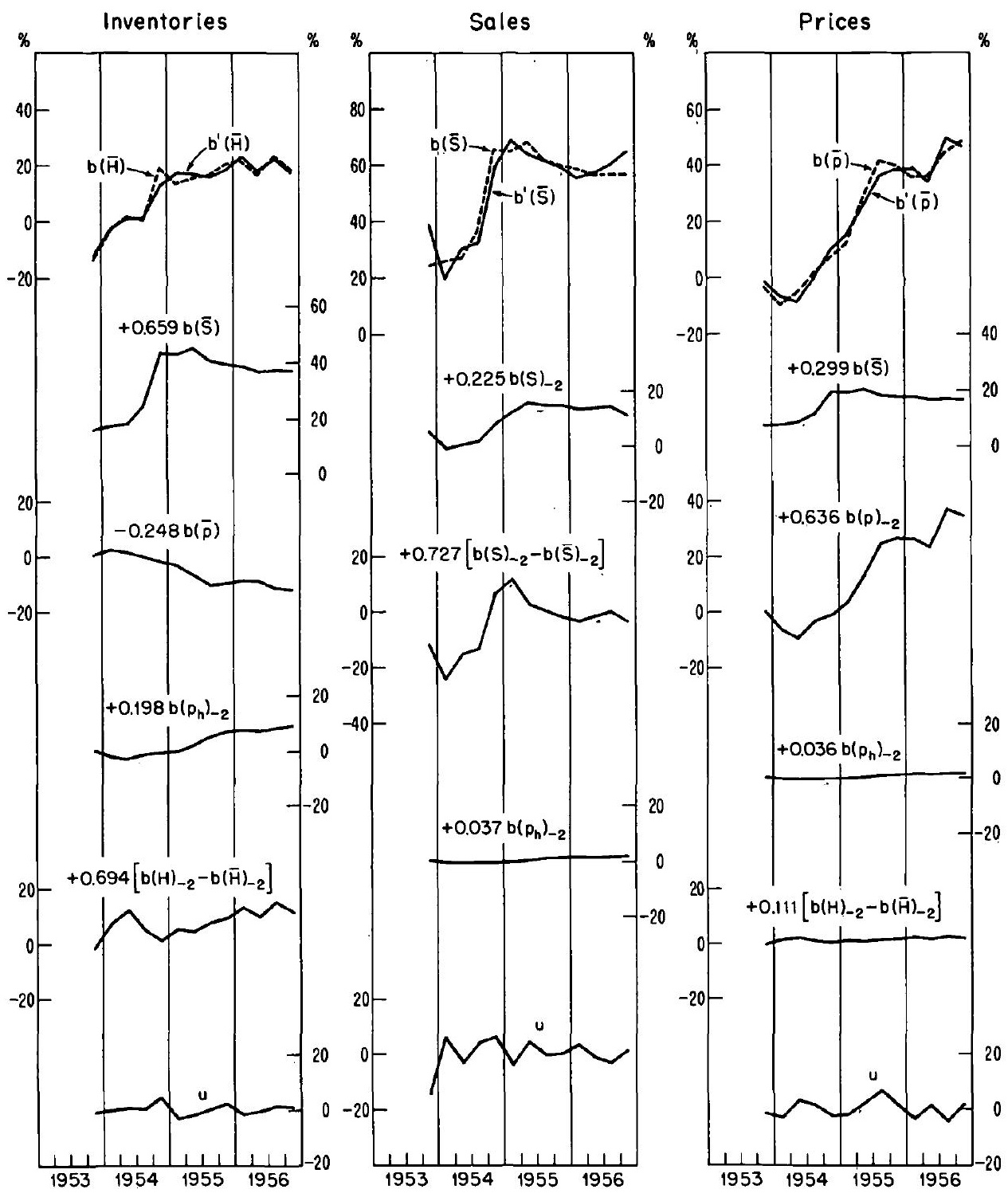

of Type II. A further consequence of collinearity is that, without exception, the standard error of the coefficient of anticipated selling prices is 
EXPECTATIONS ABOUT OPERATING VARIABLES

larger in inventory equations containing a buying-price variable than in corresponding equations without it. Thus the net gain from incorporating

CHART 6

Retail Traders, Expected Diffusion, Recursive Model with Buying Prices

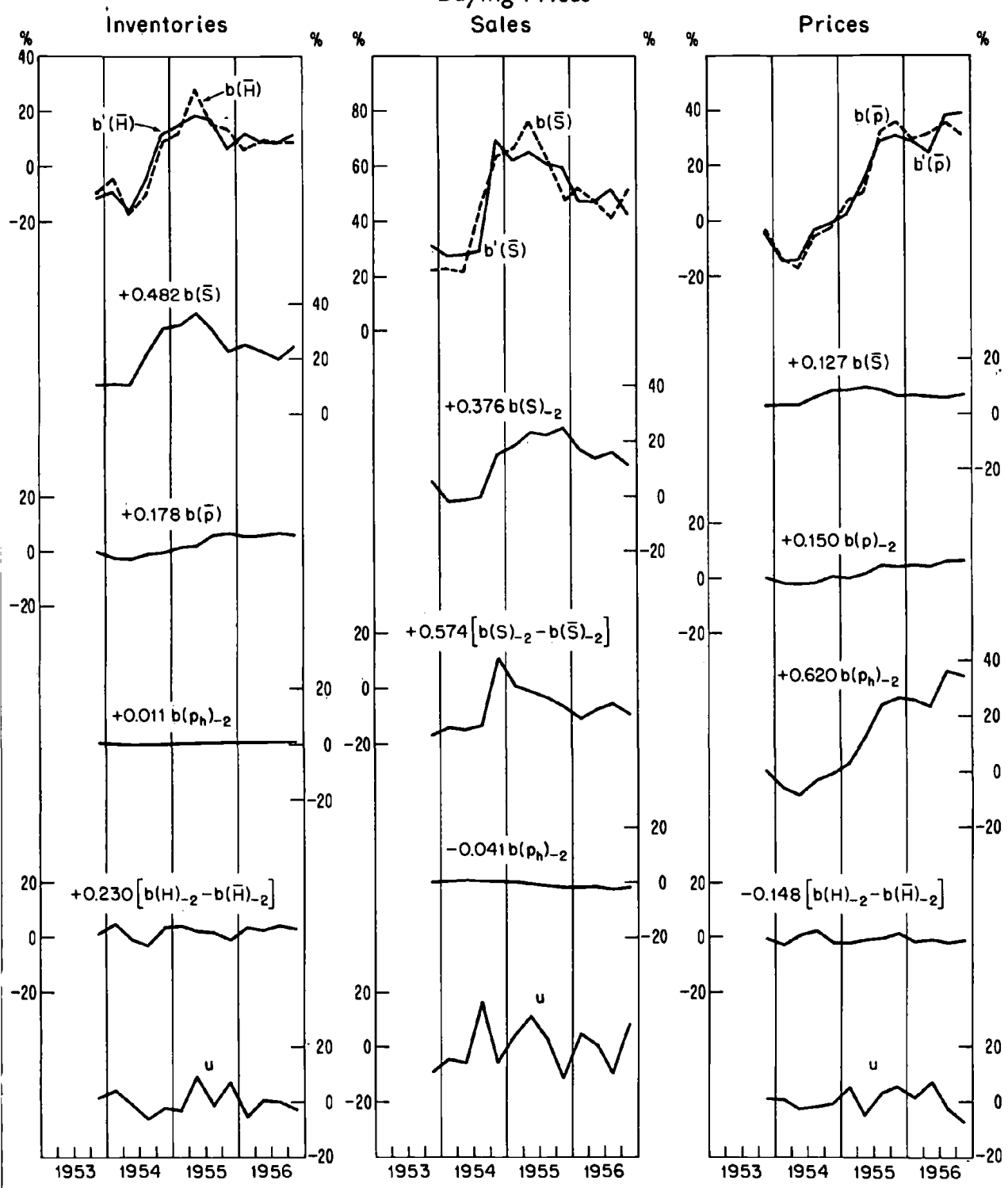

buying prices, as we can measure them, in the explanation of inventory intentions is small.

Other tendencies stand out in comparing Table 7 with Table 5. 
1. The equations for anticipated sales, though variously altered by the inclusion of buying prices, show possible improvement only in the models fitted to unweighted data.

2. In the expanded models sales expectations appear to exert more influence on the inventory intentions of wholesalers, less on the price anticipations of retailers.

3. A tendency emerges in the buying-price models for coefficients of the stock-appraisal variable to decline in numerical value. The tendency is clearest in the models fitted to weighted data of Type II, being particularly conspicuous in the reduced size of the negative coefficients in the retailers' model. This finding conflicts with the evidence of Table 5, which suggested that the largest retailers have less effective control over inventory accumulation than either wholesalers or the smaller retailers.

To round out this preliminary treatment of buying prices, Charts 5 and 6 illustrate the Type I weighted model summarized in Table 7. They bring out sharply the generally small influence of the buying-price variable except in the equations for inventory intentions of wholesalers and sellingprice anticipations of retailers.

Amended Measures of Divergence from Equilibrium. Tables 8 and 9 present the results derived from recalculations of the various models of expectation formation using amended measures of attained disequilibrium in place of the observational ones. The parallels with earlier tables will be exploited to interpret the results. However, because the present investigation is confined to unweighted diffusion data, only models previously fitted to such data, and of these only recursive models, provide an appropriate basis for comparison.

The method of estimation used was the sequential application of least squares. This method seemed suitable because of the generality of the assumptions on which it is applicable. But the danger of enhanced collinearity between explanatory variables to which it is prone turned out to be particularly troublesome and led to some wildly unstable results. Combined with the use of somewhat truncated measures of attained disequilibrium, this instability makes the interpretation of the statistical findings unusually hazardous.

Before looking into the consequences of employing the amended measures of disequilibrium, it will be well to ask whether the new calculations bear out the earlier findings about the role of buying prices in the traders' model. The question can be answered by comparing the two sections of Table 8. With allowances for the differing techniques of estimation, the contrasts here are remarkably similar to those between the unweighted data in Tables 5 and 7. Both inventory intentions and selling-price anticipations seem to be influenced by buying prices, yet in the first case the effects are largely offset by a contrary change in the influence of expected 


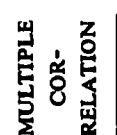

是㟧

竎

ะิ

క.

की

n + + हัँ

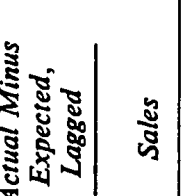

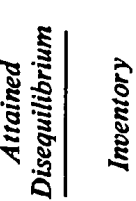

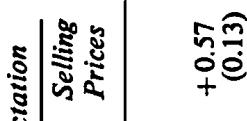

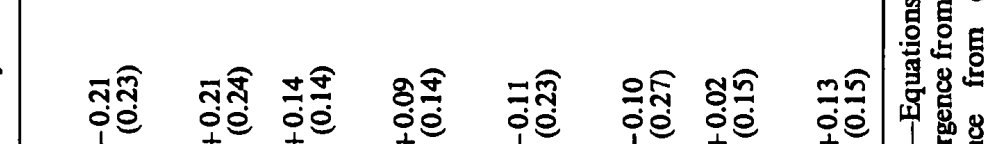

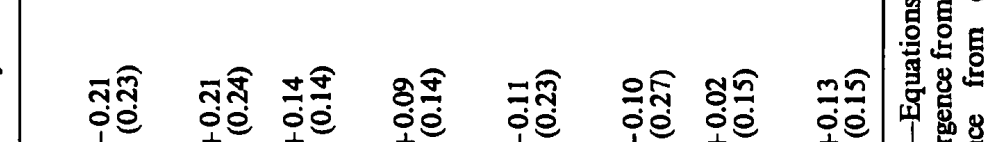

安余

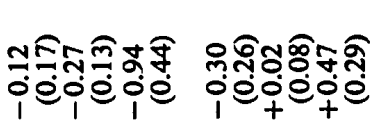

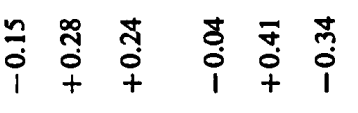

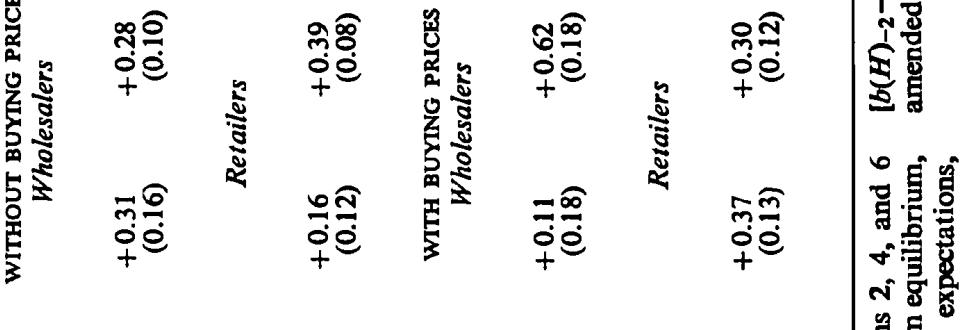

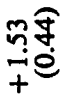

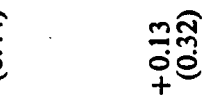

i
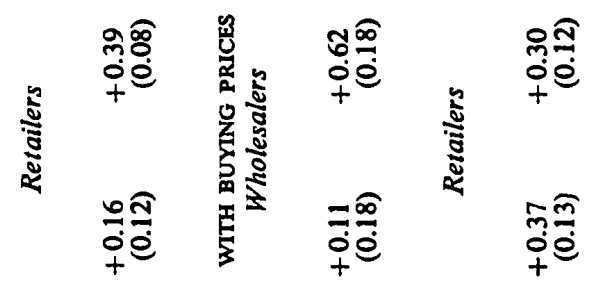

1 .

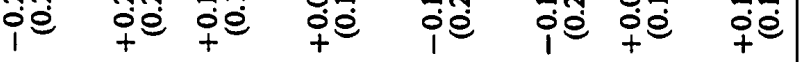

章

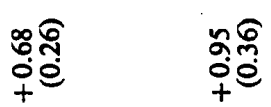

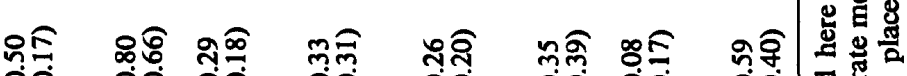

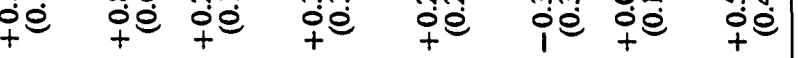

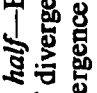

ธิ ธ: 
EXPECTATIONS ABOUT OPERATING VARIABLES

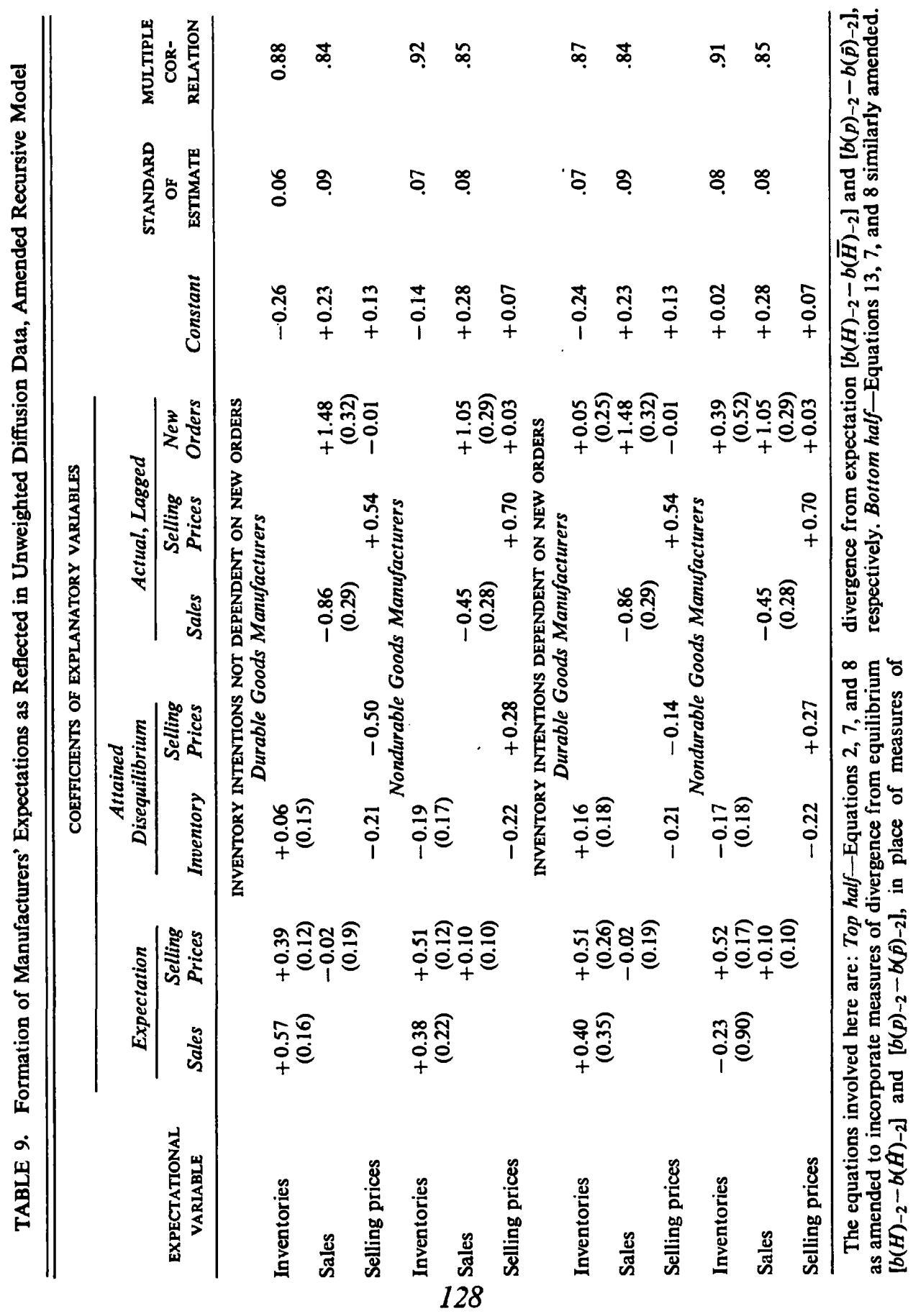


selling prices and in the second by a compensating change in the influence of realized selling prices. The rule for coefficient addition formulated for Tables 5 and 7 holds less well for Table 8, but the reason appears to be the enhanced collinearity of realized buying prices with anticipated sales and anticipated selling prices that results from the sequential method of estimation. Consistent with this interpretation is the sharp increase in standard errors of the latter two variables in the second half of Table 8. Also traceable to marked collinearity are the negative coefficient of sales anticipations in the wholesalers' equation for anticipated selling prices, and the implausibly large coefficient of anticipated selling prices in the retailers' equation for inventory intentions. By and large, therefore, the contribution of buying prices, as we can measure them, does not seem any greater in the amended traders' models than it did in the models treated earlier.

The introduction of realized new orders into the equations for manufacturers' inventory intentions is even less successful (Table 9). As measured by the adjusted coefficient of multiple correlation, the explanatory value of the inventory equations is unimproved, and the equations themselves are less plausible. Particularly unconvincing is the negative coefficient of sales anticipations in the model for nondurable goods manufacturers. Also doubtful is the apparently stronger influence of new orders on the inventory intentions of nondurable goods manufacturers than on those of durables manufacturers. Nevertheless, for the present, the results must be classed as inconclusive because of the extreme collinearity of realized new orders and anticipated sales (see their standard errors).

Turning to the amended measures of disequilibrium, we are concerned whether their introduction into the various models leads to improvements either in explanatory power or in theoretical plausibility. The amended variables are meant to be measures of disequilibria that exist at the time expectations are formed and that must be corrected for in the intentions being worked out for the future. Insofar as the measures are successful, they should carry negative coefficients in the models of expectation formation. As a practical matter, this need only be the tendency of the findings. Since the equilibrium measures are only approximations to those suggested by theory, and since the method of estimation enhances the uncertainties created by collinearity between explanatory variables, any stronger validation is not to be expected.

To study the role of the new measures in the traders' model in isolation, other aspects of the model should be held constant as well as the technique employed in its estimation. Subject to these conditions, the only comparison possible is that of Table 8 with Table 6, both of which involve the traders' model without buying prices and the sequential use of least squares. Corresponding equations of sales anticipations are identical, but other equations differ because they depend on alternative measures of the 
disequilibrium in inventory positions. The following bear on the success of the amended measures of disequilibrium:

1. Multiple correlation coefficients, adjusted for degrees of freedom, are only slightly improved by use of the new measures, except for inventory intentions of wholesalers.

2. Coefficients of the new measures of disequilibrium are always algebraically smaller than corresponding coefficients of the original measures.

3. None of these coefficients, however, is negative except in the equation for wholesalers' inventory intentions, and it was negative even in the original evaluation of the model (Table 6).

On balance, the resulting improvement of the traders' models of expectation formation is slight. The showing of the amended measures in the manufacturers' models is somewhat better. Here the appropriate comparison is between Tables 9 and 4. Note the following points:

1. Correlation coefficients for the expected selling-price relations are not available in Table 9, but all other correlations, including those for the equations of anticipated sales, are slightly higher than in Table 4.

2. Every coefficient of price and inventory disequilibrium in Table 9 is algebraically smaller than the corresponding coefficient in Table 4 .

3. Most of the coefficients of these measures are negative in Table 9. One-the coefficient of selling-price disequilibrium in the equation for expected selling prices of durable goods manufacturers-is positive in Table 4. However, the coefficients of inventory disequilibrium in the equation for inventory intentions of durable goods manufacturers, and that of selling-price disequilibrium in the equation for selling-price expectations of nondurable goods manufacturers is positive in Table 4 and remains so.

4. Realized new orders have virtually no influence on selling-price expectations in Table 9, although they seem to play a substantial role in all previous applications of the recursive manufacturers' model (see, especially, Tables 3 and 4).

Thus, while the use of the amended measures of disequilibrium in the manufacturers' model is broadly successful, there remain inconsistencies which may be traceable to the technique of estimation or to the approximations used in casting these measures in observational form.

Evidence on the Equilibrium Function. One implication of the observational form given to the amended measures of disequilibrium is that they contain implicitly the coefficients of the equilibrium function, representing desired adjustments of instrument variables ex post. Evidence on the nature of the function is marshaled in Tables 10 and 11 for manufacturers and traders.

Manufacturers are assumed to dispose of two intentions variables, 


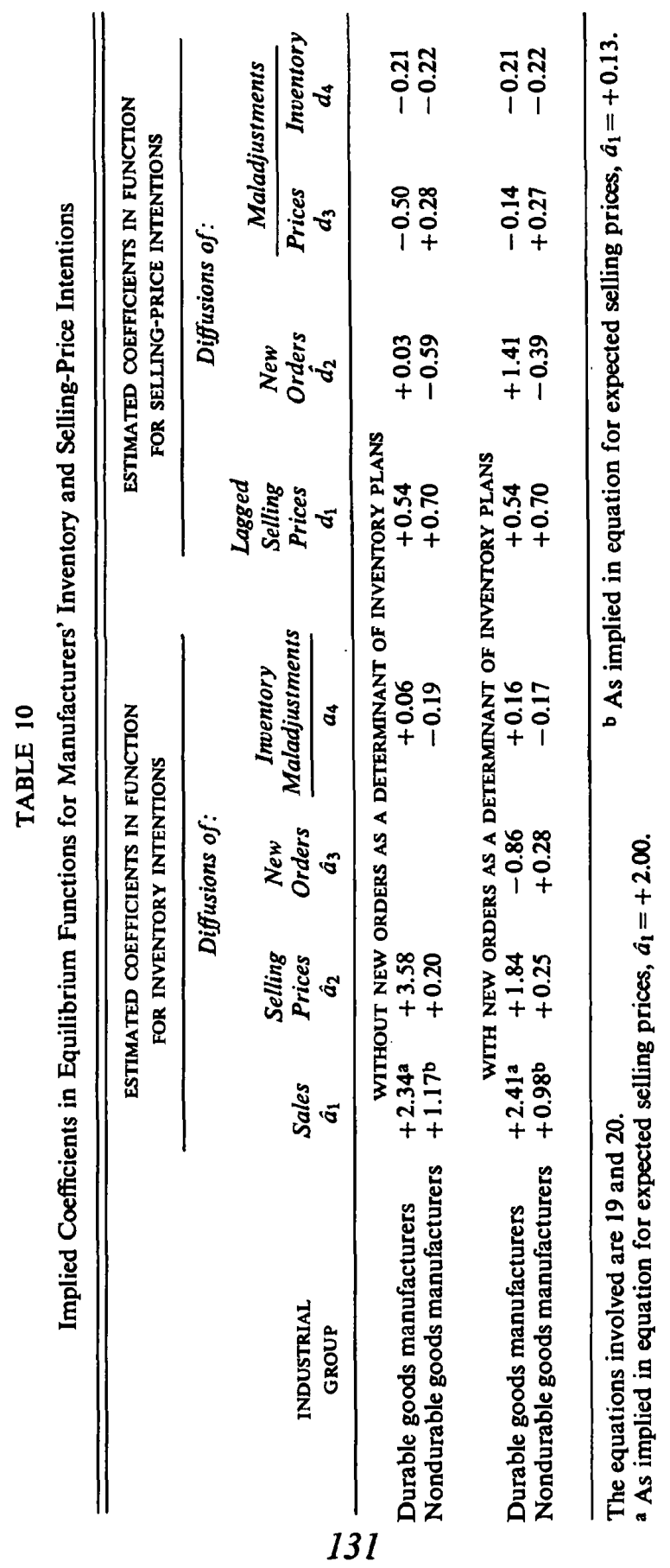


TABLE 11

Implied Coefficients in Equilibrium Function for Traders' Inventory Intentions

\begin{tabular}{|c|c|c|c|c|}
\hline \multirow[b]{2}{*}{$\begin{array}{l}\text { EQUATION FROM } \\
\text { WHICH ESTIMATES } \\
\text { ARE DERIVED }\end{array}$} & \multicolumn{4}{|c|}{ ESTIMATED EQUILIBRIUM COEFFICIENTS } \\
\hline & $\begin{array}{c}\text { Sales } \\
a_{1}\end{array}$ & $\begin{array}{c}\text { Selling } \\
\text { Prices } \\
\hat{a}_{2}\end{array}$ & $\begin{array}{c}\text { sions of: } \\
\text { Buying } \\
\text { Prices } \\
\hat{a}_{3}\end{array}$ & $\begin{array}{c}\text { Inventory } \\
\text { Maladjustments } \\
a_{4}\end{array}$ \\
\hline \multicolumn{5}{|c|}{$\begin{array}{l}\text { WITHOUT BUYING-PRICE VARIABLE } \\
\text { Wholesalers }\end{array}$} \\
\hline $\begin{array}{l}\text { Inventory intentions } \\
\text { Selling-price anticipations }\end{array}$ & $\begin{array}{l}+0.53 \\
+1.68\end{array}$ & $\begin{array}{l}-1.35 \\
-1.32\end{array}$ & & $\begin{array}{l}-0.21 \\
+0.21\end{array}$ \\
\hline \multicolumn{5}{|l|}{ Selling-price anticipations } \\
\hline Inventory intentions & -1.98 & +0.75 & & +0.14 \\
\hline Selling-price anticipations & +3.27 & -4.23 & & +0.09 \\
\hline \multicolumn{5}{|c|}{$\begin{array}{l}\text { WITH BUYING-PRICE VARIABLE } \\
\text { Wholesalers }\end{array}$} \\
\hline Inventory intentions & +1.09 & -3.42 & +0.88 & -0.11 \\
\hline \multicolumn{5}{|c|}{ Retailers } \\
\hline Inventory intentions & -7.16 & +6.16 & -0.01 & +0.02 \\
\hline Selling-price anticipàtions & +3.19 & -2.13 & -0.16 & +0.13 \\
\hline
\end{tabular}

The equation involved is 19 as modified according to text footnote 12.

inventories and selling prices. Their planning is therefore characterized by two equilibrium functions:

$$
\begin{aligned}
b(\hat{H})=a_{0}+ & \hat{a}_{1} b(S)+\hat{a}_{2} b(p)+\hat{a}_{3} b(N)+a_{4}\left[b(H)_{-2}-b(\hat{H})_{-2}\right]+v_{1} \\
b(\hat{p})= & d_{0}+d_{1} b(p)_{-2}+\hat{d}_{2} b(N)+d_{3}\left[b(p)_{-2}-b(\hat{p})_{-2}\right] \\
& +d_{4}\left[b(H)_{-2}-b(\hat{H})_{-2}\right]+v_{2}
\end{aligned}
$$

where coefficients without carets are assumed to be the same as in the corresponding planning functions. Their coefficients, as inferred from Table 9, are presented in Table 10.

The equilibrium function for inventory diffusion turns out plausibly for nondurable goods manufacturers, but less so for durable goods manufacturers. In particular, the finding that $\hat{a}_{3}<0$ and $a_{4}>0$ for the latter contradicts the theory of inventory planning with which we have been working. On the other hand, it is the durable goods manufacturers group which yields the plausible forms of the equilibrium function for sellingprice diffusion. For nondurable goods manufacturers, the results $\hat{d}_{2}<0$ and $d_{3}>0$ are inconsistent with the model. The findings thus seem at a standoff. However, the tendency of the suspect coefficients, when compared with those of earlier models, is uniformly in the right direction, and the worst contradictions are clearly associated with high collinearity of 


\section{EXPECTATIONS ABOUT OPERATING VARIABLES}

explanatory variables. The weight of the evidence thus appears to favor the general model of expectations advanced for manufacturers.

The equilibrium functions for traders is summarized in Table 11. Only a single function for inventories is involved because traders are assumed to behave as price takers. ${ }^{12}$ Lines labeled "Inventory intentions" and "Selling-price anticipations" thus represent alternative estimates of the same equilibrium coefficients, derived from different equations in the expectations model. Ideally, the alternative estimates should agree, and the extent to which they do so, is a test of the adequacy of the measures of disequilibrium, or of the method of estimation, or both.

The most striking feature of the table is the contrast between wholesalers and retailers. For wholesalers, alternative versions of the equilibrium function have coefficients of the same sign though of substantially different magnitude. For retailers, alternative versions are sharply contradictory in sign as well as magnitude. The contrast is the more surprising because the correlations for the retailers' models in Table 8 seem somewhat better than those for the wholesalers' models. However, some of the coefficients in Table 11 are unacceptably large, indicating the instability found in estimates from highly collinear data; others are unbelievably small, indicating the obverse side of the collinearity problem. Though collinearity affects the wholesalers' models, it affects the retailers' models more severely and produces unintelligible findings on the level where indirect estimates must be sought. Such collinearity may be an inescapable feature of expectational diffusion at the retailers' level, but more likely it springs from the use of overly crude approximations to the proposed measures of disequilibrium, combined with an inappropriate technique of estimation.

Despite the unfavorable showing of the estimates on the analytical level, Charts 7 through 10, which show the explanatory value of the models summarized in Tables 8 and 9, provide good explanations of the expectations actually reported by businessmen, and surpass the performance of models based on extrapolating the most recent actual diffusion of the variable in question. ${ }^{13}$ This superiority over "naïve" models extends not only to correlations but, more significantly, to matters of timing.

\section{Summary}

Research in business expectations about operating variables is a new field. It has required the invention of a new type of survey yielding a novel form of statistical information that imposes considerable strain on the technical tools developed for work with more conventional data. The findings of the paper are therefore partly methodological and partly substantive.

12 The form of the function is strictly analogous to equation 19 except that $b_{\left(P_{h}\right)}$ replaces $b(N)$.

13 Compare Hastay, pp. 118-119. 


\section{EXPECTATIONS ABOUT OPERATING VARIABLES}

\section{ESTIMATION TECHNIQUES}

Linearity. All of the models proposed to explain the generation of expectations, no less than the techniques employed to estimate them, depend for their plausibility on the analogy between diffusion data and rates of change in corresponding aggregates. In this paper the change in

\section{CHART 7}

Expected Diffusion and Estimates Derived from Amended Manufacturers' Model with New Orders a Determinant of Intended Inventory Investment,

Durable Goods Producers
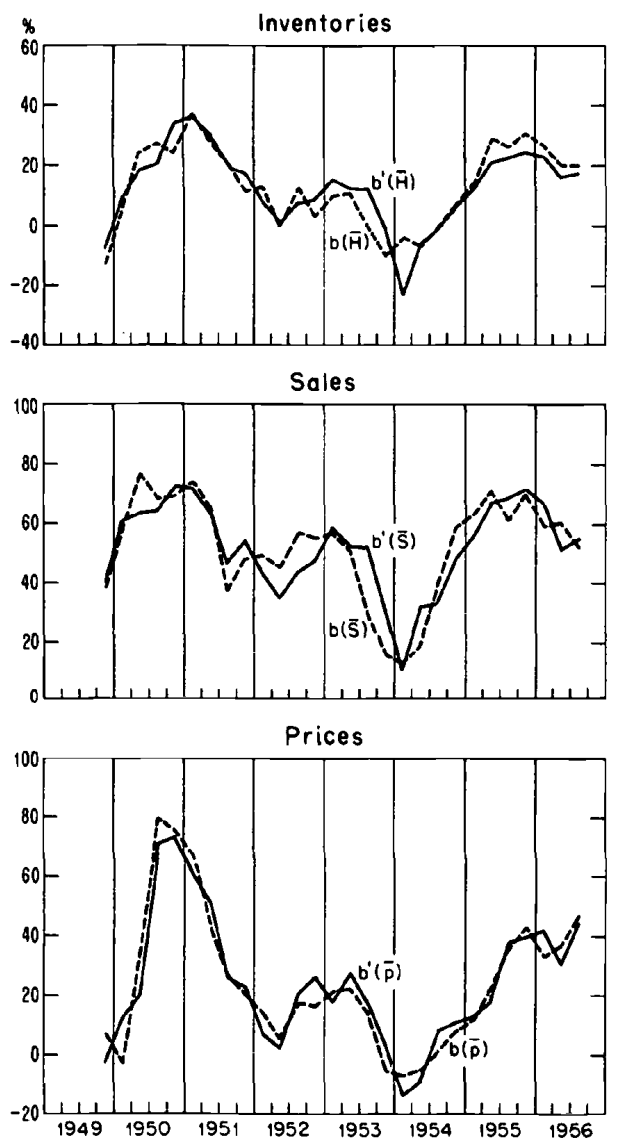

\section{CHART 8}

Expected Diffusion and Estimates Derived from Amended Manufacturers' Model with New Orders a Determinant of Intended Inventory Investment, Nondurable Goods Producers
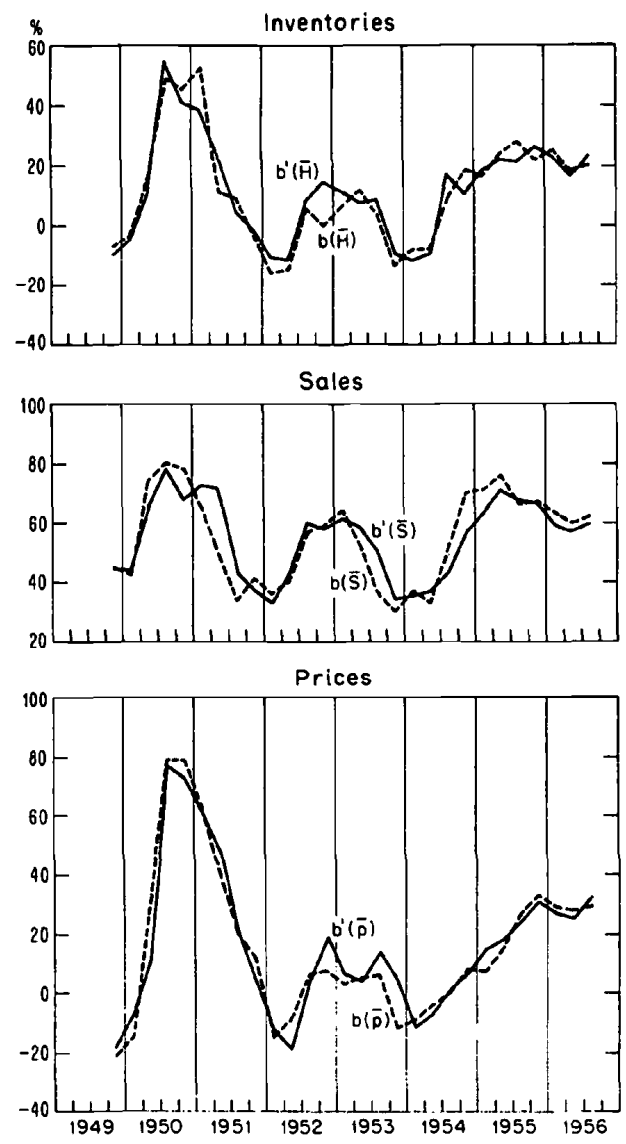
The theoretical considerations sufficient to justify the linear hypothesis rigorously are fairly restrictive, and some of the problems encountered may attest to their occasional breakdown, particularly when expectations change sharply. So far, however, I have hit on no nonlinear scheme that notably improves the relationship between measures of aggregate change and the Dun and Bradstreet data. Moreover, the importance of nonlinearities in the diffusion-aggregate change relation should be considerably reduced in models where changes are represented entirely by diffusion data.

Reliability of Estimates. More serious are the sources of instability in the coefficients estimated for the several expectation models. These include the high degree of collinearity shown by diffusion series, the sensitivity of identification in exactly identified models, and perhaps also measurement errors in the reported diffusion indexes considered as representations of diffusion in the underlying business population. All of these problems are present in the exactly identified model of expectation formation proposed for manufacturers. Even when identification is strong, the method of indirect least squares appropriate for estimating the coefficients of such models is peculiarly sensitive to multicollinearity among the endogenous variables.

Even the analysis by means of recursive models is not immune to estimation troubles. Though the models are overidentified and may be estimated by the application of least squares one equation at a time, the technique that rests on the least restrictive assumptions about the disturbances in the models is highly vulnerable to the presence of multicollinearity among the variables. This technique recognizes the interdependence of equations in each model, since current values of the explanatory variables in a given equation are derived from earlier equations in the recursive chain, beginning with the equation that depends only on exogenous variables. But such a process, while "consistent" under quite general conditions, enhances the collinearity of explanatory variables at each successive stage and may yield coefficient estimates with very large standard errors.

More stable results can be achieved by the alternative technique of estimating each equation independently. However the coefficients may be biased, for conditions on the stochastic properties of the disturbances in such models sufficient to rule out bias are quite restrictive. Since in the end the paper places chief reliance on the latter technique, the possibility of bias must be kept in mind in putting interpretations on the findings.

\section{FORMATION OF EXPECTATIONS}

Rational Interdependence of Anticipations and Intentions. While it would be an exaggeration to claim that the results of the present study reverse the prevailing impression that expectation formation is characterized by a 
low degree of rationality, they unmistakably call for corrections. Based on the interrelations of only a few key operating variables, the following findings stand out:

1. Theoretical analysis suggests that intended inventory investment depends on expected change in sales, anticipated price changes, and an appraisal of the current position of stocks. None of these influences can be measured perfectly with the data available. Inventories and sales are measured in current rather than constant dollars, and while such data are adequate to investigate the existence of an intended inventory-sales ratio, they may exaggerate the covariation of intended inventories and anticipated prices. Moreover, data on anticipated buying prices are unavailable for manufacturers, so appeal must be had to the close covariation of anticipated buying and selling prices found in other studies. Finally, the measure of the current position of stocks is indirect and requires interpretation. Yet the evidence for rationality in inventory planning remains. The assumption that businessmen plan to vary their inventories in step with anticipated changes in sales and prices provides a better explanation of the intentions they report than a more or less direct projection of past experience.

2. Theory suggests that selling-price expectations will vary in step with sales anticipations or related variables and with buying-price anticipations. Sales anticipations (for traders) or recent new order experience (for manufacturers) provide a regular, and frequently significant, determinant of selling-price expectations. And where they can be measured roughly (for traders), buying-price anticipations appear to be a sometimes influential determinant. There is also some evidence that unwanted inventories may occasionally compel a downward adjustment of price anticipations. But a far more consistent finding is that price anticipations are sluggish, depending strongly on the immediate past trend of change. None of these findings contradicts the presumption of rationality, nor can a simple scheme of extrapolation explain current price expectations so well. By the test of multiple correlations, the account of the formation of selling-price expectations is better than that for any other expectational variable, although because of their inertia they are easiest to explain.

3. The explanation of sales anticipations is least successful chiefly because of a lack of evidence on the appropriate demand determinants. For traders, a simple learning model that runs entirely in terms of past sales experience or anticipations has to be used. For manufacturers, there is evidence on price intentions and realized new orders but none on how businessmen view the general business situation or conditions in their own industries. Thus the present paper does not materially advance the explanation of sales anticipations beyond what can be accomplished by a simple extrapolation of past experience. This does not imply that sales anticipations are merely naïve projections, for results obtained by that 
method are not good either. Since our interest focuses chiefly on inventory intentions, the weakness of the analysis of sales anticipations is not serious. It hampers statistical techniques which attempt to take account of the stochastic interdependence of business expectations, but it is irrelevant to the application of single-equation least squares to the recursive structures of expectation formation, on which chief reliance was placed.

Suggestive Contrasts in the Findings. Less conclusively established by the models are certain contrasts in business behavior or anticipations:

1. In the formation of price intentions, durable goods manufacturers appear to give more weight to new order experience than do nondurables manufacturers. This reasonable result is clearest for large firms, but is not confirmed by the analysis of the unweighted data.

2. The general impression that two quarters is long enough for manufacturers to achieve a desired reversal of inventory policy may not hold in a period such as that following the start of the Korean war. More fully developed models of expectation formation will need to take account of factors limiting production in boom times.

3. Wholesalers and retailers appear to differ notably in the flexibility of inventory control. The evidence suggests that retailers often cannot reverse unwanted inventory accumulation within two quarters. However, such inertia may characterize only the largest firms, since the evidence for the contrast is considerably weaker or absent altogether when unweighted data are used.

Open Questions. Among the issues raised in this paper, but still open questions, three deserve mention:

1. The results fail to establish that new orders are a determinant of manufacturers' inventory intentions. This result would be acceptable if those answering the survey reported on finished inventory only, but the probability is that purchased materials are also considered. The failure appears to be a consequence of the extreme collinearity of new order experience and sales anticipations, both of which figure in the general equation for inventory intentions, a collinearity exaggerated by the recursive application of least squares. What is required is more data to reduce the standard errors of coefficient estimates. Beyond this, perhaps further research will yield techniques of working with diffusion data by which collinearity can be reduced. Less drastic aggregation is probably a first step, perhaps along the lines of vector techniques.

2. The effort to illuminate indirectly the equilibrium function implicit in business planning suggests that more appropriate techniques of estimation might yield conclusive findings. Given the uncertainty attending business expectations and the inevitability of disappointments, neither 


\section{EXPECTATIONS ABOUT OPERATING VARIABLES}

reported plans nor realized behavior can be interpreted as characterizing the equilibrium of the firm. In principle one could ask questions about such positions directly. Short of this, we must consult indirect evidence reflecting desired positions in the light of what has happened ex post. The approach suggested in the discussion of the equilibrium function is an avenue we might use.

3. Since reports on expected and realized changes in inventories, sales, and new orders run in value terms, they have a common element, which undoubtedly contributes to the collinearity found in the Dun and Bradstreet data and confuses the interpretation to be put on certain of the coefficients found in the models. The price factor also reduces the autonomy of the relationships found, making them dependent in some measure on a particular postwar history of chronic mild inflation. The most natural way around the difficulty is to ask businessmen for reports on changes in physical quantities. But such data are not readily obtainable, especially for multiple-product firms; and the increased difficulty of answering might cause top management to delegate the questions to less informed or responsible personnel. The choice, then, is between a subordinate's judgment of an optimum question and management's judgment of a less appropriate one. Particularly for the purpose of studying entrepreneurial expectations, the correct choice is not an obvious one.

\section{O M M E N T}

\section{ROBERT EISNER, Northwestern University}

Millard Hastay concerns himself in this rich and admirable paper with the search for functions which generate expectations. He asks whether "business expectations disclose self-consistent relations between prospects and plans and are ... meaningfully related to past experience." The skill with which he has marshaled his data and the high technical quality of his statistical analysis should be so apparent that I may perhaps be forgiven in confining myself to offering certain critical comments.

Hastay's basic data are "diffusion indexes," from the second quarter of 1950 to the third quarter of 1957, of the Dun and Bradstreet quarterly surveys of the expectations of individual firms. His underlying variables are actual and expected changes in the volume of sales, level of inventories, and level of selling prices, and, for manufacturers only, new orders received. Hastay fits linear equations designed to explain or predict, for firms in four broad industrial groups, the diffusion indexes of expected changes in the current dollar value of inventories and sales and in selling prices. His estimates are based on least-squares procedures, both direct and sequential, on the ground that his models are either exactly identified or recursive. 


\section{EXPECTATIONS ABOUT OPERATING VARIABLES}

First I shall concentrate on the economic content and value of Hastay's model. Hastay's focus is inventory investment - the inventory adjustments businessmen intend to make and the factors that shape these intentions. Expecting the diffusion of expected inventories to be positively related to sales (because of the acceleration principle), positively related to prices (because of motives of "speculation" and "risk aversion"), and negatively related to the difference between past actual and anticipated inventories (because of the stock appraisal and plan-adjusting process), Hastay gets, in fact, a number of "significant" positive coefficients for expected sales and for expected selling prices. But he gets very poor results with his stock appraisal variable and is not able to improve matters significantly by introducing a stock disequilibrium variable in its place.

I would question Hastay's formulation of the acceleration principle for inventories. As Abramovitz has emphasized, the role of the acceleration principle in explaining inventory investment is a subtle one, differing with each type of inventory. Thus while we may expect stocks of goods in process to be related positively to output and, probably, to sales, stocks of finished goods probably are negatively related to sales. Clearly the first effect of an increase in sales is to drain down existing stocks of finished goods. And as output increases, there will also be a draining down of liquid raw materials (the finished goods of suppliers) until production can be increased. Such an "anti-acceleration" effect is likely to be especially important for expectations data. For one salient fact emerging from most of the empirical investigations (explained by theoretical models of the planning process such as those of Modigliani) is that businessmen are conservative (if not reactionary) in their expressed expectations and slow to act upon expectations, which are necessarily uncertain. My own interviews with businessmen confirm that a businessman's most typical reaction to even an actual change in sales is to wait and see if it is temporary or permanent. Indeed the carrying of inventories is designed in large part to afford flexibility and allow compartmentalization of the planning horizon and delay of final decisions and action until reasonably definite information is available. Inventories give the firm time to change its rate of production if the expected change in sales actually occurs. Under this interpretation, a businessman expecting an increase in the physical volume of sales must also expect a drop in the physical volume of inventories. Hastay regards inventory expectations as intentions expressing changed production plans. To me such expectations are anticipations based upon the current production plan and anticipations of future sales which have not generally affected current production plans.

Hastay's positive regression coefficients might appear to confirm his view of inventory expectations, but because of the nature of the underlying data I am not convinced by his findings. The data out of which Hastay's variables are constructed are not physical volumes but dollar volumes. 
The significance of this fact is that price is a factor in the expression of expectations, a factor unrelated to the acceleration principle. During most of the period under review, businessmen had reason to anticipate price increases. Since when prices rise, almost everything measured in dollars also rises, they also anticipated a dollar rise in inventories and sales. This fact largely accounts for the substantial positive entries shown by the diffusion indexes and produces the marked collinearity which Hastay noted frequently and thus vitiates the reliability of most of Hastay's estimates of regression coefficients. In view of the role played by price changes, it is interesting that Hastay's coefficients of "expected" on "actual, lagged" sales for manufacturers are persistently negative (see, for example, his Tables 3 and 4). This is perhaps another confirmation (against heavy odds) of the regressive or reactionary character of shortrun expectations.

The anomaly of not correcting for price changes in models conceived in real terms also accounts for several of the inconsistencies and failures of Hastay's variables. For example, Hastay suggests that "a rise in expected buying prices should depress sales anticipations" but he fails generally to verify this conclusion. Surely, though, if a rise in buying prices is associated with a general price rise, the physical volume of sales would have to fall sufficiently to outweigh the effect of an increase in selling price for such a result to be obtained.

Hastay's paper also raises some statistical issues. His data are not the economic variables with which we are ultimately concerned but diffusion indexes, an unknown and possibly changing nonlinear transformation of relevant economic variables. I have suggested elsewhere that McGrawHill data on sales expectations indicate that the magnitudes of expected changes, as distinct from their direction, show surprisingly little relation to the magnitudes of actual changes and to other variables, thus confirming the relative usefulness of diffusion indexes for some purposes. I certainly do not wish to be construed as dismissing recent ingenious use of diffusion data. Theil, Hastay himself, and others have contributed elsewhere rigorous and perceptive analyses of some of their statistical properties and potentialities and requirements for their use. But what is the usefulness of linear regression coefficients relating one diffusion index to another? Even if I am told, as in Hastay's Table 5, that a 10 per cent increase in the difference between the diffusion indexes of actual and expected sales, lagged, is associated with an increase of 6.9 per cent in the diffusion index of expected sales, I do not know anything about the regression coefficients for the data underlying these indexes.

There is, I submit, a difficulty even more basic than the fact that Hastay gives us no parameters of the transformation of economic data into diffusion indexes, for there can hardly be a unique transformation for all variables and all periods. In the example just mentioned, the diffusion 
index for actual sales-involving presumably almost exclusively positive and negative entries - and the diffusion index for expected sales-a variable with a large "same" category-are not even remotely similar transformations of the underlying data. Yet the two are combined in one variable for which a regression coefficient is calculated. A similar combination is involved in the "inventory, actual minus expected, lagged" variable.

An associated issue relates to the meaning of standard errors of regression coefficients for small samples in which there is little or no evidence that the desired conditions for least-squares estimates are met. There is no evidence here that the variables are normally distributed or that error terms are independent, either within or between equations. Indeed, the nature of the serially correlated series of historical price changes leads me to expect high serial correlation among all of the variables and the error terms. All least-square regression coefficients relating to data extending back to 1949 would be dominated by the extreme values of the first few quarters of the Korean war (see Hastay's Charts 7 through 10). In series of twenty-seven items it will not take many pairs of extreme values to give regression coefficients that are pleasing ratios of their own "standard errors."

Finally, the overlapping and lack of independent identity of the variables contributes to the collinearity and difficulty of making reliable estimates of parameters. One special case involves the use in the sales expectations equations of one independent variable defined as "sales, actual minus expected, lagged" and another defined as "sales, actual, lagged." Actual dollar sales change for the same period thus appears as one variable and as a (probably major) element of another. More generally, Hastay relates variables that are half identical. For example, if businessmen were interviewed in July, one of the sales expectations equations would relate the change in dollar value of sales expected from the fourth quarter of the previous year to the fourth quarter of the current year with the change that occurred from the second quarter of the previous year to the second quarter of the current year. The change in actual sales from the fourth quarter of the previous year to the second quarter of the current year is thus a common element in both variables. On this count alone it would be hard again to avoid positive coefficients. This common element in variables appears also in actual, lagged, and expected inventories in the inventory expectations equations, and in actual, lagged, and expected prices in the price expectations equation. It is probably present too, indirectly, in the relation between lagged new orders and sales expectations, as well as in all relations among current expectations variables where the actual price changes of the previous six months are a common factor. This raises the serious and basic question whether positive relationships among Hastay's "expectations" variables reflect more than this common element of already realized behavior. 


\section{REPLY BY Mr. HASTAY}

Robert Eisner's comments on my paper are a vivid demonstration of the power of negative thinking. In trying to nail down his objections in brief compass, I feel like the vulture gnawing at Prometheus' liver-the job is never finished. To set limits to the task, I shall sort his criticisms into two categories: the substantive, which I shall discuss in detail, and the methodological, which I shall deal with more briefly. Under the first heading are (1) his objection to the accelerator mechanism in my inventory model, (2) his proposal of an alternative model, and (3) his denial of the suitability of diffusion data based on current dollar magnitudes to investigate my hypothesis. Under the second heading are (1) his questions about the nature of diffusion data, (2) his denial of the formal applicability of my statistical procedures, and (3) his contention that the relationships I find among diffusion data are largely spurious.

\section{METHODOLOGICAL CRITICISMS}

Now, plainly, if the methodological criticisms are valid, the substantive ones are irrelevant or inadmissible. But the demonstration that they are not valid rests largely on earlier work cited in my paper and cannot be recapitulated here. I shall therefore restrict my remarks to a few considerations designed to assure that methodological issues will be considered responsibly.

Nature of Diffusion Data. Several basic investigations, both theoretical and empirical, have dealt with the relation between diffusion data and more familiar economic aggregates. These suggest that, to a first approximation, diffusion data vary stochastically as the first difference in a corresponding aggregate, for example, that the diffusion of retailers' sales varies as the rate of change in aggregate retail sales. Sufficient conditions for this relation to hold are rather stringent, but I have published results, and have made unpublished tests, suggesting that they are tolerably well fulfilled for the Dun and Bradstreet data (see the references in footnote 5 of my paper).

Applicability of Statistical Procedures. Considering the origin of diffusion data in first differences of microvariables, it should not come as a great surprise that the stochastic aspect of the relation of diffusion data and rates of change involves apparently independent disturbances. But this fact, together with the foregoing, suffices to establish that diffusion models of economic behavior based on analogy with certain standard rate-of-change models will yield simultaneous, linear, stochastic difference-equations with serially independent disturbances. To such models, when properly identified, least-squares procedures are applicable. In denying this, in suggesting that the disturbances must be Gaussian, in confusing serial correlation with multicollinearity, in suggesting that a parametrically unique transformation of microvariables into diffusion data is necessary for all variables 
and all periods, Eisner seriously misrepresents the methodological issues of dealing with diffusion data. Moreover, in rejecting results based on small samples, Eisner misses the point of the systematic replication of experimental models presented in my paper, the aim of which is precisely to reinforce judgment from small samples. I cannot take the reader to a significance table in an elementary textbook, but the statistical world had Tchebycheff before it had Karl Pearson, and people made inductive inferences before they had either. Regrettably, the evidence leaves room for difference of opinion; but what it calls for is hard thought, not a throwing up of hands.

Spuriousness of Diffusion Relations. But what about the point that Dun and Bradstreet expected and realized diffusion data overlap in time and thus contain a common element of realized experience? This is admittedly a source of part correlation, or what Karl Pearson labeled pejoratively "spurious" correlation. If none of his other criticisms hold up, Eisner suggests that this property alone may account for all or most of the apparent relationships I have exhibited. I submit that this objection is insupportable in the light of my paper of September 1954, where I demonstrate the independent predictive value of the part of expected diffusion data that is not included in overlapping data on realized diffusion. Moreover, the expected magnitude of the "spurious" correlation implied is, on any realistic assumptions, significantly less than any of the correlations found. I agree, however, that it would be useful to be able to break down the Dun and Bradstreet diffusion data into nonoverlapping segments; and a beginning has been made with a special question on manufacturers' new orders recently adjoined to the Dun and Bradstreet questionnaires. Since the resulting two-quarter diffusion series are potentially affected by seasonal variations, it is not yet possible to present empirical estimates of the magnitude of part correlation between expected and realized diffusion as currently compiled by Dun and Bradstreet, but a provisional examination of the data bears out my earlier findings that the purely forward-looking part of Dun and Bradstreet expectations is significantly and substantially correlated with subsequent realized behavior. (See Basic Research and the Analysis of Current Business Conditions, 36th Annual Report, National Bureau of Economic Research, May 1956, pp. 29-31.)

\section{SUBSTANTIVE CRITICISMS}

Acceleration Principle. Eisner contends that the evidence is all against a model of inventory expectations based on an accelerator mechanism, even when modified by allowance for the current position of stocks. The evidence cited is (1) Abramovitz' monograph on inventories, (2) the claim that Dun and Bradstreet inventory expectations cannot be treated as "intentions," or goals of action, but only as supine "anticipations" of 


\section{EXPECTATIONS ABOUT OPERATING VARIABLES}

the outcome of impersonal market forces, and (3) the fact that businessmen are conservative in their diagnoses of the future.

1. Now, the appeal to Abramovitz is beside the point. I deal with inventory plans, he with realized inventories. What actually happens to inventory-sales ratios is irrelevant in view of the widely attested result that businessmen's desired inventory adjustments are frequently unrealized because of business-cycle developments. Eisner would have us disregard this evidence and assume that the realized behavior of inventories is what businessmen plan-surely a novel view of the matter, but one for which he will find little support in Abramovitz.

In short, Eisner's is a model of realized inventory behavior masquerading as a model of expectations. Producers of finished staples may, in fact, be able to tolerate substantial departures from planned inventory goais; but it is not very plausible to assume that they cooperate with the inevitable to the extent of planning things that way.

2. Eisner, however, contends that Dun and Bradstreet expectations have nothing to do with plans or intentions, and it must be admitted that the question whether they do is a reasonable one. For periods of a few weeks to a month, it is probable that inventory expectations are, in fact, anticipations about changes over which the firm has little deliberate control. But over six months, for firms whose average stocks are three months' sales, the element of deliberate intention must be dominant in inventory expectations, and it is these which are reported in the Dun and Bradstreet surveys.

3. Nothing in this view of expectations, or in my models, is hostile to the idea that businessmen are conservative in their inventory planning. I expect them to underrespond to uncertain data by the test of what would seem right in retrospect, though I do not follow Eisner in expecting them not to respond at all. But the question of conservatism cannot be answered by expectational models alone. It is a matter not only of the signs of coefficients, but also of their size; and questions of size require investigations along the lines of my "equilibrium hypothesis."

Diffusion in Current Dollars and Inventory Planning. It will be convenient to discuss the second and third of Eisner's substantive criticisms together. Eisner contends that the acceleration principle does not apply to current dollar magnitudes, and that the assumption that it does masks my failure to see that an alternative inventory model really characterizes businessmen's expectations. I propose to upset both contentions.

1. My defense of an acceleration model for dollar magnitudes rests on the interesting work of Henri Theil and his associates, which shows that actual and expected selling prices are largely determined by actual and expected buying prices, respectively, for the same period, and that little 
else in the way of significant determinants of selling prices is to be found in diffusion data (see the reference in footnote 6 of my paper). Let us assume, therefore:

a. That equilibrium physical stocks, $H$, are intended to be a constant proportion, $\beta$, of the physical quantity of sales, $Q$

b. That finished stocks are priced at market

c. That raw materials and finished goods prices vary in step.

By the simple acceleration principle we have

$$
\begin{aligned}
H & =\beta Q \\
H_{1}-H_{0} & =\beta\left(Q_{1}-Q_{0}\right)
\end{aligned}
$$

Let price in time 0 be denoted $P$; in time $1, P+\Delta P$. Then in dollar terms $H_{1}-H_{0}$ becomes

$$
(P+\Delta P) H_{1}-P H_{0}=P\left(H_{1}-H_{0}\right)+(\Delta P) H_{1}
$$

and $Q_{1}-Q_{0}$ becomes

$$
(P+\Delta P) Q_{1}-P Q_{0}=P\left(Q_{1}-Q_{0}\right)+(\Delta P) Q_{1}
$$

But if the acceleration principle applies, we have

$$
\begin{gathered}
P\left(H_{1}-H_{0}\right)=\beta P\left(Q_{1}-Q_{0}\right), \text { with } P \text { a common multiplier } \\
(\Delta P) H_{1}=\beta(\Delta P) Q_{1}, \text { with } \Delta P \text { a common multiplier. }
\end{gathered}
$$

Adding gives

$$
P\left(H_{1}-H_{0}\right)+(\Delta P) H_{1}=\beta\left[P\left(Q_{1}-Q_{0}\right)+(\Delta P) Q_{1}\right]
$$

or

$$
(P+\Delta P) H_{1}-P H_{0}=\beta\left[(P+\Delta P) Q_{1}-P Q_{0}\right]
$$

i.e. the acceleration principle applies to dollar magnitudes for finished inventories. A similar argument holds for purchased materials in view of the close relation of buying and selling prices.

2. Consider the alternative model proposed by Eisner, viz. inventories a passive shock absorber of sales variations. In physical terms, this can be written

$$
H_{1}-H_{0}=-1\left(Q_{1}-Q_{0}\right)
$$

where equilibrium stocks are meant to satisfy $H=\beta Q$. In dollar terms, we have to re-evaluate equation 3 . Employing the equilibrium assumption and (7), we can write

$$
H_{1}=H_{0}+\left(H_{1}-H_{0}\right)=\beta Q_{0}-\left(Q_{1}-Q_{0}\right)
$$

thus

$$
\begin{gathered}
(\Delta P) H_{1}=(\Delta P) \beta Q_{0}-(\Delta P)\left(Q_{1}-Q_{0}\right) \\
146
\end{gathered}
$$


From (7)

$$
P\left(H_{1}-H_{0}\right)=-P\left(Q_{1}-Q_{0}\right)
$$

Adding (9) and (10) gives

$$
(P+\Delta P) H_{1}-P H_{0}=-(P+\Delta P)(\Delta Q)+(\Delta P) \beta Q_{0}
$$

Now, Eisner contends that the negative shock-absorber relation (7) becomes a positive relation in the form (11). But let us recall that, in terms of the questions asked by Dun and Bradstreet, the survey variables are based on first differences in four-quarter moving averages at annual rates. Thus the flow variables $Q$ are of annual magnitude and the accelerator may be supposed to average about $\beta=1 / 4$; that is, average stocks about three months supply. Then for "Eisner's effect" to be overshadowed by price effects, we must have

$$
(\Delta P) \beta Q_{0}>P_{1}(\Delta Q)
$$

that is,

$$
(\Delta P) / P_{1}>(1 \Delta / \beta)\left[(Q) / Q_{0}\right]
$$

which requires that price change must be $1 / \beta=4$ times quantity change. In other words,

$$
\text { Amplitude ratio }=\frac{\Delta P}{P}: \frac{\Delta Q}{Q}=4: 1
$$

But, generally speaking, this degree of price flexibility does not exist in manufacturing and trade. I conclude, therefore, that Eisner's alternative inventory model implies negative acceleration coefficients in the Dun and Bradstreet data except under assumptions known to be contrary to fact.

To summarize, we see that:

a. If the acceleration principle applies to physical quantities, it will hold as between dollar magnitudes as well.

b. If Eisner's counterprinciple applies-that is, $\Delta H$ is the inverse of $\Delta Q$-then negative coefficients should hold even between dollar magnitudes unless (i) average stocks are a large fraction of one year's supply, or (ii) price flexibility is very great.

3. On one point, Eisner's observations on the price factor in Dun and Bradstreet inventory and sales data must be accepted: it does contribute to the multicollinearity that afflicts certain of the models involving buying and selling prices. It does not, however, "vitiate" the reliability of my estimates of regression coefficients; it increases their standard errors in a way that is fully registered in their reported sizes. The more important point is one that I make in my summary: it reduces the autonomy of my expectational relations, making them in some degree dependent on a particular history of chronic postwar inflation. But some coefficients are more affected by this loss of autonomy than others, the acceleration 
coefficients least of all. I submit, therefore, that Eisner's case against my acceleration hypothesis falls to the ground.

Relation of Buying-Price and Sales Anticipations. A final point is interesting as a matter of tactics. Eisner quotes me as saying that "a rise in expected buying prices should depress sales anticipations." He does not quote my next sentence: "But since price rises are frequently associated with improved business, the final impact may be negligible or even positive:" My expectation of an initial depressive effect of expected buyingprice increases on anticipated sales revenue is based on the belief that most business firms conceive their demand curves to be elastic; this is why they meet competition. It would imply negative marginal revenue if they did not so believe. And without any direct experience of the sort, it is hard to see why they should imagine total revenue for the industry to go up in consequence of a cost-induced rise in prices-unless in a general expansion of the volume of business, which is recognized in my unquoted sentence.

The positive relations generally found between expected buying prices and anticipated sales is thus not unanticipated in my comments, which in fact cover Eisner's explanation as a speciál case of increasing aggregate demand. 